ANSP-M-2

FEBRUARY 1972

Copy. No.

43

Aerospace Nuclear Safety Program

\title{
PIONEER F/SNAP 19 \\ HEAT SOURCE ABLATION STUDIES
}

by D. W. CONN

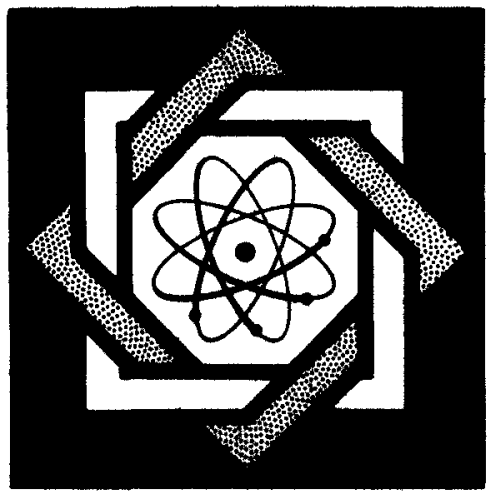

THE JOHNS HOPKINS UNIVERSITY • APPLIED PHYSICS LABORATORY

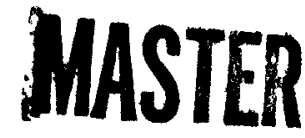

DISTRIBUTION OE THIS DOCUMENT IS UNLIMITED 


\section{DISCLAIMER}

This report was prepared as an account of work sponsored by an agency of the United States Government. Neither the United States Government nor any agency Thereof, nor any of their employees, makes any warranty, express or implied, or assumes any legal liability or responsibility for the accuracy, completeness, or usefulness of any information, apparatus, product, or process disclosed, or represents that its use would not infringe privately owned rights. Reference herein to any specific commercial product, process, or service by trade name, trademark, manufacturer, or otherwise does not necessarily constitute or imply its endorsement, recommendation, or favoring by the United States Government or any agency thereof. The views and opinions of authors expressed herein do not necessarily state or reflect those of the United States Government or any agency thereof. 


\section{DISCLAIMER}

Portions of this document may be illegible in electronic image products. Images are produced from the best available original document. 
ANSP-M-2

FEBRUARY 1972

Aerospace Nuclear Safety Program

PIONEER F/SNAP 19
HEAT SOURCE ABLATION STUDIES

by D. W. CONN

This repurt was prepared as an account of work
sponsored by the United States Government Neither
the United States nor the United States Atomic Energy
Commission, nor any of ther employees, nor any of
their contractors subcontractors, or their employees,
makes any warranty express or implied, or assumes any
legal liability or responsibility for the accuracy, com
pleteness or usefulness of any information, apparatus,
product of process disclosed, or represents that its use
would not infringe privately owned rights

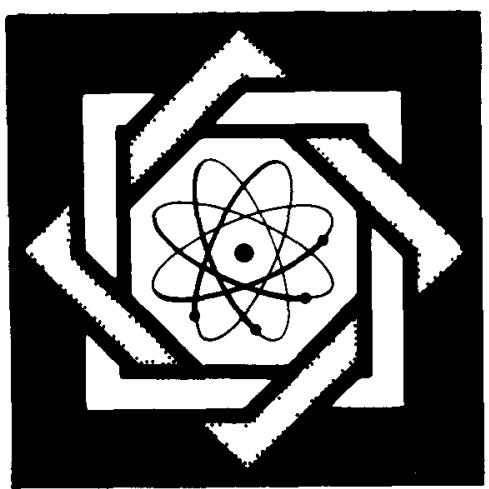

THE JOHNS HOPKINS UNIVERSITY • APPLIED PHYSICS LABORATORY

8621 Georgıa Avenue 。 Sılver Sprıng, Maryland 。 20910

Operating under Contract N00017 72-C-4401 with the Department of the Navy

DISTRIBUTION OF THIS LUW LI IS UNLMMTED

$+$ 
THE JOHNS HOPKINS UNIVERSITY APPLIED PHYSICS LABORATORY

SLLVER SPRING MARYLAND

\section{FORWARD}

The work reported herein was conducted by the Applied Physics Laboratory Aeronautics Division for the Atomic Energy Commission, Safety Branch, Space Nuclear Systems Office. Activities of the Aeronautics Division are under the general supervision of Dr. William H. Avery. The Project Engineer for the Aerospace Nuclear Safety Program is James C. Hagan. 
A series of studies were conducted to assess the ablation performance of the Pioneer F/SNAP 19 heat source for various analytical thermochemical and mechanical erosion models. One of the specific objectives of this study was to evaluate the oxidation cut-off concept employed in past reentry safety analyses versus more physically representative oxidation models. It also afforded an opportunity to obtain a gross assessment of heat shield performance for oxidation models representative of the graphite mass loss data measured at (a) General Electric and (b) NASA Langley Research Center. These studies were extended to investigate the effects of different graphite sublimation models on heat shield performance and attempted to consider "mechanical erosion" effects heretofore omitted in reentry safety analyses.

Fina11y, uncertainties present in current graphite ablation predictive techniques and specifically, within the recommended model of these studies are discussed and demonstrated in terms of heat source ablation performance. 
A series of studies were conducted to assess the reentry ablation performance of the Pioneer F/SNAP 19 heat source for various analytical thermochemistry and mechanical erosion mode1s. Results of the oxidation studies indicated the simple oxidation cut-off mode1 used in Teledyne-Isotope's safety analysis can be justified only if the cut-off temperature is specified at about $1500^{\circ} \mathrm{F}$. This specification essentially equates the model to the Fast Rate mode1 (Fig. 2) and will predict slightly conservative (higher) oxidation losses when compared to APL's currently recommended Moderate Rate oxidation mode1. The oxidation studies further indicated a significant amount of heat shield recession can be attributed to oxidation during subsonic reentry (typically, 50 to 55 mils for shallow reentries). A gross model (Very Slow Mode1, Figure 2) of NASA Langley's oxidation data was evaluated against the Moderate Rate mode1 (which represents G.E. data) for effects on heat shield performance for an orbital decay reentry. The results indicated a 50\% reduction in predicted heat shield recession for the Very Slow model. The NASA Langley data and G.E. data are currently in conflict and, from this gross comparison, can yield substantial differences in predicted heat shield performance. The mechanical erosion effect resulted in total heat shield recession varying from a $25 \%$ increase over thermochemical predictions to prompt ablation failure. Uncertainties within the APL recommended model include formulation solely on the basis of experimental ATJ ablation data 
and absence of pressure effects in the mechanical erosion model. Uncertainties of a more basic nature concern the true kinetic mechanisms of carbon oxidation and the thermodynamic characteristics of the higher order carbon vapor species forming during sublimation at elevated temperatures. APL's model has assumed a conservative position in light of limitations and/or uncertainties within the available data. Significant refinements in graphite ablation modelling will require (a) extended experimental research to precisely define the fundamental aspects of carbon oxidation and vaporization and (b) an extended experimental data base for graphite materials of current interest in heat source designs. 


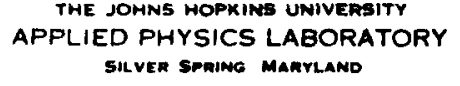

TABLE OF CONTENTS

I. INTRODUCTION

II. OXIDATION STUDIES

A. Odixadtion Cut-off Concept

B. Oxidation Models

C. Therma1 Mode1 and Surface Energy Balance

D. Results and Discussion

III. SUBLIMATION STUDIES
A. Sublimation Mode1s
B. Results and Discussion
C. Mechanical Erosion Models
D. Results and Discussion

IV. ABLATION MODEL UNCERTAINTIES

A. Oxidation Mode11ing

B. Mechanical Erosion and Sublimation Modelling

C. Summary

V. PIONEER F HEAT SOURCE ABLATION FAILURE STUDY

A. $V-\gamma$ Failure Space

B. Discussion

VI. CONCLUSIONS

REFERENCES

NOMENCLATURE

TABLES AND FIGURES 
THE JOHNS MOPKINS UNIVERSITY APPLIED PHYSICS LABORATORY SILVER SPRING MARYLAND
LIST OF TABLES

Table I

Effects of Oxidation Mode1s on Reentry Thermal Performance, Pioneer $F$ Heat Source

Table II

Summary of Ablation Failure Study, Pioneer F Heat Source 
THE JOWNS MOPKINE UNIVERSITY APPLIED PHYSICS LABORATORY

SILVEN SPMING MANYLAND

Fig. 1 Oxidation Cut-Off Concept

Fig. 2 Comparison of Graphite Thermochemical Ablation Models and Experimental Data

Fig. 3 Pioneer F SNAP 19 Heat Source Thermal Mode1

Fig. $\quad 4 \quad$ Surface Energy Balance

Fig. 5 Thermochemical Recession Profiles, Orbital Decay Reentry

Fig. 6 Comparison of Component Temperatures for Different Oxidation Models, Orbital Decay Reentry

Fig. 7 The rmochemical Recession Profiles, $-8^{\circ} / 40 \mathrm{~K}$ fps Reentry

Fig. 8 Mechanical Erosion Models

Fig. 9 Effect of Mechanical Erosion on Total Recession, $-8 \%$ 40K fps Reentry

Fig. 10 Effect of Mechanical Erosion on Total Recession for Severe Sublimation Environment, $-12^{\circ} / 42 \mathrm{~K}$ fps Reentry

Fig. 11 Estimated $v_{-} \gamma_{i}$ Boundary for Heat Shield Ablation Failure

Fig. 12 Estimated Incremental $v_{i}-\gamma_{i}$ Space (Prompt Reentry) for Atmospheric Fuel Release 


\section{INTRODUCTION}

The oxidation cut-off concept has been used both by Sandia and Teledyne-Isotopes in their Pioneer F SNAP 19 heat source reentry safety analyses. It has been indicated by both Sandia ${ }^{(1)}$ and APL ${ }^{(2)}$ that this approach for determining oxidation effects can lead to significant differences in predicted graphite recession as well as moderate differences in structural impact temperature depending upon the choice of the cut-off temperature. This memo reports on a study that evaluated the cut-off concept by examining more physically representative oxidation models for several Pioneer $F$ heat source reentries. It also permitted an opportunity to obtain a gross assessment of the effects on heat shield performance for oxidation models representative of (a) the G.E. experimental graphite mass loss data (3) and (b) the NASA Langley data of Maahs (4) and Miller/ Sutton (5). Additionally, the study was extended to investigate the effect of widely varying graphite sublimation models on heat shield performance and attempts to consider "mechanical e rosion" effects heretofore omitted in reentry safety analyses. 


\section{OXIDATION STUDIES}

\section{A. Oxidation Cut-Off Concept}

The continuous curve in Figure 1 depicts the classical oxidation rate profile experienced by a reactive surface under boundary layer influences and is characterized by reaction rate controlled, transitional and diffusion-limited oxidation regimes. A1though the precise shape of this rate profile, which suggests a simple Arrhenius kinetic behavior, can be argued in light of current investigations (e.g., Maahs ${ }^{(6)}$ and Baron and Bernstein ${ }^{(7)}$ ), it does serve to indicate the basic regimes that should be considered in an oxidation model. The oxidation cut-off concept represents a simplification of this profile as illustrated by the dashed lines in Figure 1. This simplified model indicates that above a specified surface temperature, oxidation proceeds at a diffusion limited rate whereas below it, oxidation is inhibited. The basic weakness of this model is the general lack of criteria for selection of a cut-off temperature.

\section{B. Oxidation Mode1s}

Perini ${ }^{(8)}$ has recently conducted a survey on both the theoretical and experimental aspects of graphite ablation. A result of this survey was a compilation of experimental oxidation data for ATJ graphite as shown in Figure 2. The oxidation mass loss data have been normalized by the corresponding diffusion limited rate, $\mathrm{m}_{\mathrm{D}}$. The literature showed ATJ to be the only artificial grade of graphite that was extensively tested over the total oxidation regime. Data on the Poco graphites (current heat shield materials for RTG heat sources) were piecemeal and generally 
THE JOHNS HOPKINS UNIVERSITY

APPLIED PHYSICS LABORATORY

SUIVEn SPRING MAMYLAND

lacked supporting data to permit normalization in the manner shown in Figure 2. The compilation can be described by two basic sets of data within the rate controlled and transitional oxidation regimes; that is, the data set owing basically to the investigations at G.E. (3) and the data set from the investigations at NASA Langley $(4,5)$. These sets of data are conflicting and have been a continuing subject for discussion at past Pioneer $F$ nuclear safety review meetings. The NASA Langley data represent a portion of the data base that has led Maahs ${ }^{(6)}$ to suspect that kinetic controlling mechanisms may be prominent in determining graphite oxidation losses at temperature levels previously thought to be solely diffusion-1imited. To date, the causes for the differences in these data sets have not been resolved.

Figure 2 also includes several classical oxidation models that bracket the experimental data. Specifically, the "Fast" Rate model provides a left hand extremum, the "Very Slow" Rate a right hand extremum while the "Moderate" Rate model provides a reasonable representation of the large data set measured at G.E. One of the recommendations resulting from the APL survey was to use the Moderate Rate mode1 to predict oxidation behavior for graphite. This recommendation is not to be interpreted as a refutation of the NASA Langley data but rather one which models a data base that yields greater ablation predictions. This is in keeping with the general philosophy of conservatism for reentry safety analyses when confronted with uncertainties (in this instance, experimental oxidation data). 
THE JOHNS HOPKINS UNIVERSITY
APPLIED PHYSICS LABORATORY

Silven Spaing maktLand

It was decided to evaluate the Fast, Moderate and Very Slow oxidation models for a common Pioneer $F$ heat source reentry. The orbital decay reentry was selected for this purpose since heat shield surface temperatures are limited to the oxidation regime, (i.e., less than $5000^{\circ} \mathrm{F}$ ). An evaluation of this type is meaningful for the following considerations:

(1) Oxidation sensitivity can be established between APL's current recommended Moderate Rate Model and the extreme Fast Rate Mode1.

(2) The Very Slow Rate Model is a gross representation of the NASA Langley oxidation data. Therefore, a comparison of this model with the Moderate Rate Model will give an indication of the sensitivity on heat shield oxidation response resulting from the conflicting data sets of G.E. and NASA Langley.

(3) Finally, a comparison of the Fast and Slow Rate Models will index the bounds on heat shield oxidation response as dictated hy the currently observed range of experimental graphite oxidation data.

\section{Thermal Model and Surface Energy Balance}

The thermal model shown in Figure 3 is a one-dimensional cross section of the Pioneer $F$ heat source at the windward, mid-span, stagnation location for a flat leading, side-on-stable reentry attitude. This mode 1 considered temperature dependent the rmal properties, a fixed gap distribution and a specific fuel power leve1 
THE JOHNS HOPKINS UNIVERSITY

APPLIED PHYSICS LABORATORY

SILVER SPRING Marylano

as defined in the T-I thermal analyses. The model is intended solely to assess the effect on ablation response of the various oxidation models previously discussed in Subsection B. The resulting temperature data should be viewed solely on a comparative basis rather than per se since the model is void of circumferential conduction effects.

The general surface energy balance for this study is shown in Figure 4 and is modeled after the phase interface control volume concept of spalding ${ }^{(9)}$. With exception of the surface enthalpy fluxes, the indicated energy components are self explanatory (see Nomenclature). Solid carbon represents the transferred substance at the interface, being introduced into the control volume in its solid state at the rate, $\dot{m}_{L}$, and removed at a rate $\dot{m}_{L}^{*}$, due to particulate erosion, and at $\dot{\mathrm{m}}_{\mathrm{S}}$ in a gaseous state due to thermochemical transformation. Consequently, the resulting enthalpy $f$ lux, $\mathrm{m}_{\mathrm{S}} \mathrm{h}_{\mathrm{S}}$, results from the heterogeneous reaction of solid carbon with boundary layer oxidants wherein (a) $h_{S}$ is the resulting sensible and chemical enthalpy of the reaction products based on equilibrium thermochemistry and (b) $\dot{m}_{S}$ is the mass loss rate based on the oxidation models of Figure 2 . Equilibrium surface the rmochemistry solutions were obtained from the EST ${ }^{(10)}$ and/or NOTS ${ }^{(11)}$ computer codes for the simplifying assumptions of unity Lewis Number and equal specie diffusion coefficients. These thermochemistry data were utilized in solving the governing surface energy balance and resulting in-depth thermal response of the heat source model via the CMA code ${ }^{(12)}$. 
THE JOHNS HOPKINS UNIVERSITY

APPLIED PHYSICS LABORATORY

SILVER SPRING MAAYLAND

\section{Results and Discussion}

The results of the orbital decay reentry analysis are summarized in Table 1 in terms of the heat source's critical design parameters, i.e., total heat shield recession, clad member peak temperature and strength member impact temperature. A comparison of heat shield recession histories during the heat pulse and terminal phases of reentry is shown in Figure 5. The Fast and Moderate Rate oxidation models do not yield substantial differences in either predicted recession or structural temperatures. The Fast mode1 predicted $4 \%$ greater total recession than the Moderate model due to (a) earlier initiation of oxidation during reentry and (b) continued operation in the diffusion limited regime during terminal reentry. This small difference would be even further reduced for steeper reentries due to faster surface temperature transients. It is noted in this figure that a significant amount of recession (.055") occurs during the subsonic terminal phase of reentry.

The Very $\mathrm{Sl}$ low oxidation model causes a $50 \%$ reduction in recession from the levels predicted for the Fast and Moderate models. Although a portion of this difference can be attributed to the oxidation model's flatter profile, the principal effect is shown in Figure 5 to be the inhibition of oxidation during the final 200 seconds of flight. This, of course, relates to the termination of oxidation effects at or below approximately $2100^{\circ} \mathrm{F}$ as defined by this model. It is of interest to note that a $2100^{\circ} \mathrm{F}$ surface temperature occurs at approximately Mach 1 with 
THE JOHNS HOPKINS UNIVERSITY

APPLIED PHYSICS LABORATORY

SILVER SPRING MARYLAND

the Fast and Moderate Rate models. Consequently, if a $2100^{\circ} \mathrm{F}$ cutoff temperature was specified for an oxidation cut-off model (as considered in the T-I analyses), the entire subsonic recession profile shown in Figure 5 would be unaccounted for within the analysis. This illustrates the hazard of over-specifying a cutoff temperature when employing an oxidation cut-off model.

Table 1 indicates a negligible effect from the various oxidation models on predicted peak clad temperatures. However, the Very Slow model results in predicted strength member impact temperatures 90 to $100^{\circ} \mathrm{F}$ lower than the other models which again points to the absence of surface oxidation effects during terminal reentry. Figure 6 compares the strength member temperature and heat shield surface temperature histories during teminal reentry for the Fast and Very Slow Rate oxidation cases. The divergence in temperature response of the strength member results from differences in radial heat transfer during cool-down due to significant differences in the response of the shield's surface temperatures. The shield temperature resulting from the Very Slow model continues to decay due to an absence of exothermic heating to the surface attributable to carbon oxidation. On the other hand, exothermic heating from the Fast model sustains surface temperatures at significantly higher levels. It is noted that the surface temperature for the Fast model remains at a sufficient level to sustain carbon oxidation at a diffusion limited rate throughout the entire reentry flight period. This is an important observation since an identical behavior would 
THE JOHNS HOPKINS UNIVERSITY APPLIED PHYSICS LABORATORY SILVER SPRING MARYLAND

be obtained from an oxidation cut-off model if the cut-off temperature is specified at a sufficiently low value. It is further noted that the rapid kinetics of the Fast Rate model results in a profile which approximates an oxidation cut-off model at a cutoff surface temperature of about $1500^{\circ} \mathrm{F}$. Consequently, it would appear the cut-off oxidation concept can be justified in heat source reentry analyses if the cut-off criterion is specified at a temperature level of about $1500^{\circ} \mathrm{F}$ rather than at the higher levels as employed in past safety analyses. The $1500^{\circ} \mathrm{F}$ criterion would essentially equate the cut-off model to the Fast Rate model and, as noted from this study, will predict slightly higher oxidation losses than obtained from the recommended Moderate Rate mode 1. 


\section{A. Sublimation Models}

APL's survey ${ }^{(8)}$ of graphite ablation behavior also included the sublimation regime. The experimental ATJ data of Lundel1 and Dickey ${ }^{(13)}$ were the only quality graphite data found within the sublimation regime for a stagnation pressure range synonomous with heat source reentries. This data set is also shown in Figure 2 for a 1 atmosphere pressure level. The data set has been used by APL as the basis for selection of a recommended sublimation mode1. In that Lunde11 and Dickey observed mechanical erosion effects during ablation of their test specimens, it is reasonable to expect thermochemical predictions of sublimation to be somewhat less than the measured data for comparable surface temperature and pressure conditions. On this basis, APL has currently selected a JANAF (69) equilibrium model to provide thermochemical predictions ${ }^{(8)}$. This model is shown in Figure 2 to fall slightly below the experimental data in the sublimation temperature range. Figure 2 also indicates the Scala model (14) compares reasonably well with the JANAF model except at the extreme temperatures. The thermochemical model of Dolton, et. al. (15) represents an extreme for determining sublimation rates and is shown in Figure 2 to vastly overpredict Lunde11 and Dickey's experimental data set. It was decided to investigate heat shield performance for a typical superorbital reentry (i.e., a. $8 \% / 40 \mathrm{~K}$ fps initial flight condition) for both the Dolton and JANAF thermochemical sublimation models. The 
THE JOHNS MOPKINS UNIVERSITY

APPLIED PHYSICS LABORATORY

SILVER SPRING MaRYLAMD

same heat source thermal model and surface energy balance as described in Figures 3 and 4 were considered in these studies. B. Results and Discussion

Figure 7 compares recession profiles for a $-8^{\circ} / 40 \mathrm{~K}$ fps superorbital reentry resulting from (a) the three oxidation models discussed in Section II coupled with the APL recommended JANAF sublimation mode 1 and (b) the APL recommended Moderate Rate oxidation mode1 coupled with the conservative Do1ton sublimation model. Differences in recession for Curves 1,2 and 3 do not occur until the heat shield experiences cool-down. The effects of the different oxidation models are the same as previously discussed for the orbital decay analysis. Note once again the small differences in recession resulting between the Fast and Moderate oxidation models. Furthermore, the use of a $2100^{\circ} \mathrm{F}$ cut-off temperature would again eliminate the entire subsonic recession region. The discrete effects of the various oxidation models on recession are not sizable during the early period of the heat pulse (35 to 40 second) due to rapid surface temperature transients. Comparison of Curve 4 with Curve 2 (the APL recommended total thermochemistry mode1) illustrates the effects of the different sublimation mode1s. The large sublimation rates occurring with the Dolton mode1 (e.g., at 50 seconds) leads to eventual burn through of the heat shield. The comparison emphasizes the point that rational criteria must be used in selecting a thermochemistry mode 1 (Lunde11 and Dickey's experimental data set in this case) rather than merely choosing the extreme conservative model for 
THE JOHNS MOPKINS UNIVERSITY APPLIED PHYSICS LABORATORY SIIVER SPRING MARYLAND

ablation calculations. The use of Dolton's sublimation model for the Pioneer $F$ heat source ablation analyses would have probably identified a substantial $V-\gamma$ ablation failure space.

\section{Mechanica1 Erosion Mode1s}

The results of Figure 7 are based on thermochemical recession predictions only. This analysis was extended to include mechanical erosion effects in the manner suggested by Lunde11 and Dickey ${ }^{(13)}$. Specifically, the data set of Lundell and Dickey was reduced to a 'mechanical erosion' component by predicting, via the JANAF (69) model, the thermochemical component at each data point's respective temperature and pressure condition. Therefore, to provide proper context, mechanical erosion is defined herein as the difference between measured data and the currently recommended thermochemical model predictions. This scheme is discussed in further detail in (8). The resulting reduced data are shown in Figure 8 and do not indicate any discernible pressure effect over the pressure range of the test series (i.e., .5-4 atm). Consequently, a curve fit through the data was determined solely as a function of surface temperature ${ }^{(8)}$ and is defined as Model 1 in Figure 8. It should be noted, however, that this model appears to be statistically biased at the extreme temperatures $\left(>3750^{\circ} \mathrm{K}\right)$ since (a) there is a paucity of data in this region and (b) the existent high temperature data were collected solely at the higher pressure test conditions. Therefore, an alternate mechanical erosion model (simple step function) was additionally examined which assumed the mechanical 
erosion component to remain fixed at a constant level with surface temperature as dictated by the lower pressure conditions. This model is defined as Model 2 in Figure 8 . These models were subsequently incorporated into the ablation analyses to address the "mechanical erosion" effect.

\section{Results and Discussion}

The $-8 \% / 40 \mathrm{~K}$ reentry was re-analyzed to include the effects of mechanical erosion Models 1 and 2. The results of this analysis are shown by the recession profiles in Figure 9. The comparative effects between Mode1 1 and Mode1 2 on total recession are not particularly significant for this reentry. However, the general effect of mechanical erosion on total recession is substantial, amounting to $25 \%$ of the predicted thermochemical recession at time of impact. It is of interest to note for this particular reentry that the heat shield burns through at approximately the time of impact for the Model 1 case and constitutes a boundary condition for ablation failure of the Pioneer $F$ heat source in $V-\not s p a c e$. Heat shield surface temperatures for the $-8 / 40 \mathrm{~K}$ reentry did not reach levels to permit discrimination of the two mechanical erosion models. Consequently, a more severe reentry was analyzed to examine the effects of higher surface temperatures on mechanical erosion. Figure 10 presents a similar comparison of recession profiles for a severe $-12 \% / 42 \mathrm{~K}$ reentry. This comparison shows total recession to have an alarmingly high sensitivity to the mechanical erosion models and specifically relates to the questionable high temperature 
region ( 3750 to $4000^{\circ} \mathrm{K}$ ) previous $1 \mathrm{y}$ discussed in Figure 8 .

Ablation failure occurs within the sublimation period of flight for Model 1 since surface temperatures exceed $7000^{\circ} \mathrm{R}$ $\left(3880^{\circ} \mathrm{K}\right)$ and corresponding mechanical erosion rates are equivalent or in excess of predicted thermochemical rates. The heat shield survives the sublimation period for the less severe Mode1 2 and does not indicate failure until approximately time of impact (oxidation burn through). The important conclusion to be drawn from this analysis is that the introduction of the mechanical erosion effect, a refinement heretofore neglected in nuclear reentry safety analyses, has in turn introduced a new element of uncertainty into reentry analyses. Once again, in keeping with a conservative policy for safety analyses, APL is inclined to favor the more severe Mode1 1 to assess mechanical erosion effects. However, it is abundantly clear that more experimental data are required to clarify the 'erosion' effect at the higher surface temperatures for pressure conditions of interest (i.e., $\mathrm{P}_{\tilde{S}} 0-5 \mathrm{~atm}$ ). 
It has been indicated in this report and e1sewhere ${ }^{(8)}$ that APL currently favors (a) the Moderate Rate oxidation mode1 (Figure 2), (b) the JANAF (69) sublimation mode1 (Figure 2) and mechanical erosion Mode1 1 (Figure 8) to predict ablation behavior of graphite. It has further been shown that these models have been founded on a seemingly rational application of available experimental graphite ablation data. Furthermore, where uncertainties appear within the data, a conservative posture has been taken in selecting models for reentry safety ablation analyses. At this point, it might prove worthwhile to discuss these uncertainties in somewhat further detail. A. Oxidation Modelling

It has been previously indicated in section II that the graphite oxidation data measured at General Electric and at NASA Langley are in conflict. The contradiction of these data sets has currently led to the selection of a model (Moderate Rate) representative of the G.E. data simply by virtue of its more conservative nature. The comparison of recession losses between the Moderate and Very Slow Rate models in Table 1 showed significant differences in ablation performance as constituted by these data sets. Although the Very Slow Mode1 is admittedly a very gross representation of the Langley data, these results indicate substantial gains to be realized in heat shield performance should one choose to implement the Langley data. However, justification for this data basically involves knowing the true kinectic mechanism(s) 
relating to carbon oxidation and it is herein that uncertainty currently exists. An evaluation of a substantial body of experimental graphite oxidation data has led Maahs $(4,6)$ to surmise that kinetic mechanisms may persist to very high surface temperatures and are alien to the Arrhenius form generally assumed in oxidation studies. These investigations of Maahs merit serious consideration. Unfortunately, research of this type has not been pursued to the extent where a universal kinetic mechanism can now be identified with carbon oxidation. Maahs' recommendation of using a specific rate expression that provides correlation with the experimental data of Golovina and Khaustovich is made categorically for all artificial graphites. However, it is well known that oxidation characteristic vary for different grades of graphite due to such effects as impurity levels, binder to particle ratio, porosity, etc. Although Maahs' investigations are acknowledged and encouraged, it does not appear that the recommended rate expression resulting from these studies to date has sufficient substance to supplant the Arrhenius based oxidation model as recommended by APL ${ }^{(8)}$ for reentry safety analyses. One other area of uncertainty related to the oxidation studies of this report centers about the current model being dictated solely on the basis of observed data for ATJ graphite. As previous1y mentioned, oxidation characteristics vary for different graphitic materials due to inherent differences in microstructure. Consequently, model refinement becomes contingent upon acquiring a similar data base for the graphites being considered in heat source designs (i.e., POCO grades currently, 
THE JOHNS HOPKINS UNIVERSITY APPLIED PHYSICS LABORATORY SILVER SPRING. MARYLAND

possibly carbon/carbon composites in the future) to permit evaluation of rate constants, etc. as required for any presumed kinetic mechanism. It should be noted that a limited amount of oxidation data for the Pioneer F shield material, POCO AXF-Q1, became available from TeledyneIsotopes toward the conclusion of this study. These data have been included in Figure 2 and show good agreement with the currently recommended Moderate Rate model at these lower temperatures. However, it is too limited a data base to validate the model for this particular graphite grade.

B. Mechanical Erosion and Sublimation Modelling

It was indicated in Section III that the inclusion of mechanical erosion effects in reentry analyses has introduced still another uncertainty which merits consideration. Based on Lunde11 and Dickey's data set as a reference, the resulting mechanical erosion Mode1 1 has been formulated on the basis that pressure effects are not influential at the lower pressure levels (0-5 atm) and is in conformance with Lundel1 and Dickey's observations. It was shown in Figure 10 that this supposition leads to severe ablation losses in evaluating the Pioneer $F$ heat source performance as opposed to a simple-minded erosion model (Model 2) that was intended to represent low pressure conditions. Intuitively, it does not appear that the pressure parameter should be neglected in the pressure range for current heat source reentries solely on the basis of the reduced data resulting from Lundell and Dickey's investigations. On the contrary, pressure levels provide an index to the aerodynamic forces acting on the body which are a prime impetus in removing particulate matter. Clearly, 
THE JOHNS HOPKINS UNIVERSITY

APPLIED PHYSICS LABORATORY

SILVER SPRING MARYLAND

resolution of this pressure effect is tied to acquiring a larger data base, particularly at conditions of high surface temperature and low pressures where the recommended erosion model is currently biased. Once again, it is of importance to acquire sublimation data specifically for graphites being considered in heat source designs. Ideally, sublimation is considered to be strictly a surface mechanism and consequently independent of graphite microstructure. Realistically, it is related to microstructure due to sub-surface sublimation effects resulting from macro and micro-pore distributions within the material. Although the uncertainty of pressure effects on mechanical erosion modelling has been directly demonstrated in terms of this Pioneer $F$ study, there is an underlying uncertainty of a more basic nature that additionally requires consideration. At this time, there is no universal quantitative model for determining mechanical erosion effects as a function of both graphite microstructure and the thermochemical environment. Furthermore, it does not appear hopeful that such a model will be forthcoming in the reasonably near future. Consequent1y, mechanical erosion models probably will continue to be formulated from reduced experimental data in the manner previously described in Subsection III,C. Therefore, model refinement for determining mechanical erosion behavior becomes contingent upon accurate definition of the basic thermochemical sublimation process. It has long been observed that vaporization of carbon results in a multicomponent mixture of carbon vapor species as opposed to a vapor with a singular molecular structure $\left(\mathrm{e} . \mathrm{g} \cdot, \mathrm{C}_{1}(\mathrm{~g})\right)$. The JANAF (69) model employed in this study considers carbon vapor species $\mathrm{C}_{1}$ through $\mathrm{C}_{5}$ constrained to a condition of the rmochemical equilibria. 
Whereas the heats of formation and thermodynamic functions of species $\mathrm{C}_{1}$ and $\mathrm{C}_{2}$ issued by JANAF are genera1ly accepted, there is dispute regarding the properties for $\mathrm{C}_{3}$. The $\mathrm{C}_{3}$ specie is of critical importance in modelling the graphite sublimation process since (a) it is a very active molecule during carbon vaporization over a broad temperature range and (b) generally provides the foundation for estimating the the rmodynamic properties for $\mathrm{C}_{4}$ and higher order carbon species (e.g., the method of Pitzer and Clementi ${ }^{(16)}$ ). The rationale for the JANAF $\mathrm{C}_{3}$ thermodynamic functions and resultingly, the estimations for $\mathrm{C}_{4}$ and $C_{5}$, is that they provide good correlation with the experimental equilibria vapor pressure data of Drowart, et. al ${ }^{(17)}$ obtained in the limited temperature range of 2000 to $3000^{\circ} \mathrm{K}$. The uncertainty regarding this model, or any model for that matter, relates to the verity of the thermodynamic functions extended to temperatures in excess of $3000^{\circ} \mathrm{K}$. Another uncertainty of perhaps lesser importance is the absence of higher order molecular species (i.e. $\mathrm{C}_{6}$ and above) in the model. Inclusion of these species again would require estimation of the molecular properties based principally on the $\mathrm{C}_{3}$ characterization. The excellent review on carbon vaporization by Palmer and Shelef ${ }^{(18)}$ further indicates that the influence of $\mathrm{C}_{6}$ and $\mathrm{C}_{7}$ in an equilibrium system does not appear significant until temperatures are in excess of $4500^{\circ} \mathrm{K}$. This temperature condition would be in excess of surface temperatures currently associated with heat source reentries (approximately $\leq 4000^{\circ} \mathrm{K}$ ). There is also the question of whether kinetics are prominent in the formation of these higher order species (i.e. $\mathrm{T} \leq 4000^{\circ} \mathrm{K}$ ) which in turn introduces uncertainties currently registered with available 
evaporation coefficient data. At any rate, the presence of kinetic influences would act to further reduce the concentrations of higher order species at the surface temperature levels of current interest. Although these higher order species do not appear to be significant for heat source ablation, experimental data are required to validate this premise.

In reviewing the above uncertainties, one might ask how they effect the results of this study? By forcing total recession (i.e. thermochemical and mechanical) to approximately match the Lundell and Dickey data as indicated in this study, it becomes important to understand what percentage of this data is attributable to thermochemical effects. If it can be shown that the uncertainties result in a larger thermochemical loss than predicted by the current JANAF (69) model, the effect should be to reduce surface temperatures due to larger endothermic energy considerations in the surface energy balances. A reduction in surface temperature would act to reduce the mechanical erosion component as currently indicated in Mode1 1 (Figure 8) and enhance ablation performance. It is intuitively felt that any subsequent changes to APL's currently endorsed sublimation model would behave in the above manner and thereby reduce predicted ablation losses. C. Summary

The discussion of uncertainties in this section has attempted to provide recognition that the state of the art in graphite ablation modelling has by no means achieved a final, glorious state. These discussions clearly indicate that further broad refinements in ablation modelling are contingent upon the following considerations: 
THE JOMNS MOPKINS UNIVERSITY APPLIED PHYSICS LABORATORY SILVER SPRING MARYLAND

1. An extended experimental ablation data base in both the oxidation and sublimation regimes is necessary for the graphitic materials currently being considered in heat source designs. Low pressure sublimation data are particularly important for assessing pressure effects on mechanical erosion modelling at the extreme surface temperature conditions.

2. High 1y controlled experimental research remains necessary to acquire a basic definition of (a) the kinetic mechanisms of carbon oxidation and (b) the the modynamic and kinetic characteristics of higher order molecular carbon vapor species. Specifically, the work of Maahs has provided a fresh insight to carbon oxidation at elevated temperatures and should be pursued on recognition of the potential gains to be realized in heat source ablation performance. Furthermore, carbon vaporization research should be particularly directed toward (a) refining the heats of formation data for species $\mathrm{C}_{3}$ through $\mathrm{C}_{7}$ as well as (b) validating their thermodynamic functions at temperatures in excess of $3000^{\circ} \mathrm{K}$ for immediate benefits in refining heat source sublimation calculations. 
The effects of uncertainties inherent within current graplite ablation models can further be dramatized by extending the sublimation studies of Section III in superorbital $\mathrm{v}-\gamma$ space. The limited studies of Section III identified an ablation failure mode for the Pioneer $F$ heat source for certain prompt reentries based on APL's current recommended ablation model. It was later indicated in Section IV that the recommended ablation model implies a posture of conservatism in view of current uncertainties regarding graphite ablation behavior. This section addresses a brief follow-on study which attempted to define a $\mathrm{V}-\gamma$ ablation failure boundary for the Pioneer $F$ heat source based on APL's current ablation mode1 (i.e., Moderate Rate oxidation, JANAF (69) sublimation and Mode1 1 mechanical erosion models).

\section{A. $\quad v-\gamma$ Failure space}

A total of 15 superorbital reentries were examined using the thermal structural model and surface energy balance defined previously in Section II (Figures 3 and 4). The resulting vertical failure boundary shown in Figure 11 was derived from the criterion of total heat shield recession at approximately time of impact. The multiple skin region had previously been identified as an ablation failure zone in Teledyne-Isotope's safety analysis (19). Consequently, the skip boundary constitutes a lower boundary for the purposes of this study. The upper boundary in this region is dictated by the heat shield's thermal stress failure boundary. Since this study has been conducted on the basis of nominal analyses 
THE JOHNS MOPKINS UNIVERSITY

APPLIED PHYSICS LABORATORY

SILVEN SPRING MARYLAND

(as opposed to error analyses with variation of parameters), the nominal $\mathrm{V}-\gamma$ maximum stress plots determined by Teledyne-Isotopes (Fig. IV-88, Ref. 19) were used in defining a stress failure boundary. Teledyne-Isotopes indicated in the final Pioneer $F$ safety review that stress calculations should be increased by $10 \%$ to account for various factors not previously considered in their stress calculations. On the basis of the nominal $\mathrm{V}-\gamma$ stress map and the $10 \%$ correction factor, a relocated stress failure boundary was estimated and is shown in Figure 12. The region encompassed by the thermal stress failure boundary, ablation failure boundary and the multiple skip boundary represents the $V-\gamma$ space yielding ablation failure of the heat shield during prompt reentry. Based on trajectory conditions at the time of heat shield failure, a fuel capsule melt failure boundary was estimated as shown in Figure 12. Unfortunately, time did not permit the boundary to be substantiated via analyses prior to the Pioneer F World Hazard Review Meeting. The melt failure boundary tacitly implies that the fuel capsule is immediately released to the atmosphere upon heat shield failure. The terminal or release conditions associated with the 15 ablation analyses are summarized in Table 2. The crosshatched $V-\gamma$ space to the right of the melt boundary provides an estimate of the region yielding atmospheric fuel release due to an ablation failure mode. This nominal failure space was reported at the World Hazard Review Meeting. 
THE JOMNS HOPKINS UNIVERSITY APPLIED PHYSICS LABORATORY SILVER SPRING MARYLAND

\section{B. Discussion}

The failure space resulting from heat shield ablation failures during reentry have been derived on the basis of nominal analyses. To remain consistent with the Teledyne-Isotope's safety analyses, this failure mode should be evaluated on the basis of an error analysis in the manner conducted for the heat shield thermal stress failures. Although time did not permit such an analysis prior to the final Pioneer $F$ safety review meeting, some observations can be made regarding the possible outcome.

In constructing an error analysis, one must be conscious not only of the uncertainties related to data per se (e.g., thermal properties) but also to uncertainties related to technique. Consequently, an ablation error analysis must not only consider many of the uncertainties addressed by Teledyne-Isotopes in their thermal stress analysis but also give prime attention to the uncertainties related to ablation modelling as discussed in Section IV. It is clear that consideration of the modelling uncertainties would act to shift the ablation failure boundary to the right in Figure 12 and thereby reduce fuel release probabilities. This can be illustrated by isolating attention to the mechanical erosion effect. One could have chosen mechanical erosion Model 2 rather than Model 1 (Figure 8) to perform the failure study. It could be argued that this model more closely reflects reentry conditions since, as indicated in Table 2, maximum stagnation pressures within the V- $\gamma$ failure space of interest generally do not exceed two atmospheres. An indication of the outcome using Mode1 2 can be obtained from the 
results for the $-12 / 42 \mathrm{~K}$ reentry previously discussed in Figure 10 . This figure shows ablation failure to shift to approximately time of impact for the Mode1 2 mechanical erosion behavior and intimates the ablation failure boundary in Figure 11 probably shifts to the $42 \mathrm{~K}$ velocity coordinate. It follows that any additional variation considered for ablation modelling uncertainties (for example, an oxidation model reflecting the NASA Langley data) will further shift this boundary and reduce the $V-\gamma$ failure space and associated fuel release probabilities. In view of the large sensitivities associated with these uncertainties (e.g., mechanical erosion models in Figure 10) it is reasonable to expect that ablation failures predicted for the Pioneer $F$ heat source by an error analysis should be minimal and not significantly alter the atmospheric fuel release probabilities reported by Teledyne-Isotopes. However, in conclusion, the thrust of this exercise is not so much related to the discussion of Pioneer $F$ heat source failure probabilities per se as it is to re-emphasizing the need to resolve the uncertainties related to graphite ablation predictive techniques through extended experimental investigations. It should be recognized that within our current framework of knowledge regarding graphite ablation behavior, consideration of these uncertainties in future error analyses of heat source systems will be largely subjective and may well be of more critical importance than indicated herein for the Pioneer $F$ system. The other alternative, of course, is to adhere to a conservatively oriented ablation model (as currently considered by $\mathrm{APL}$ ) and incorporate existing uncertainties as penalties into the design of future heat source assemblies. 
VI. CONCLUSIONS

A series of studies were conducted to assess the ablation performance of the Pioneer F/SNAP 19 heat source for various analytical thermochemistry and mechanical erosion models and was supplemented with a discussion on uncertainties currently contained within the APL model and with graphite ablation predictive techniques in general. Conclusions from these studies are as follows:

A. Oxidation Studies

1. The simple oxidation cut-off model can be justified for estimating oxidation rates if the cut-off temperature is specified at about $1500^{\circ} \mathrm{F}$. This specification will essentially (a) equate the cut-off model to the Fast Rate oxidation model (Figure 2) which slightly over-predicts recession and (b) predicts equivalent structural temperatures when compared to the current recommended Moderate Rate model results.

2. A significant amount of heat shield recession results from graphite oxidation during the subsonic period of reentry (typically, 50 to $55 \mathrm{mils}$ for shallow reentries). A portion or all of this subsonic recession may well be omitted in an ablation analysis utilizing an oxidation cut-off mode 1 if a cut-off temperature is over-specified $\left(\mathrm{e} . \mathrm{g} ., 2100^{\circ} \mathrm{F}\right)$.

3. The Very slow Rate model, which is a very gross representation of the NASA Langley data, results in about a $50 \%$ reduction in predicted heat shield recession from the value predicted by the G.E. derived Moderate Rate model for an orbital decay reentry. This crude comparison serves to illustrate the 
THE JOHNS HOPKINS UNIVERSITY APPLIED PHYSICS LABORATORY SILVER SPRING MARYLAND

substantial differences in ablation performance that can result from these conflicting data sets.

B. Sublimation and Mechanical Erosion Studies

1. Mechanical erosion is an important consideration in assessing heat shield ablation performance that has, heretofore, been omitted in nuclear reentry safety analyses. These studies have shown this effect to result in added recession during sublimation conditions that ranged from (a) a $25 \%$ increase over thermochemical predictions to (b) prompt ablation failure of the heat shield for various superorbital reentries.

2. The pressure effect on mechanical erosion is not currently included in the mechanical erosion model and has indications of being a decisive factor in determining graphite ablation for high energy reentries.

3. The sublimation model proposed by Dolton et al represents an ultra-conservative thermochemical model in terms of the Lundell and Dickey data and lead to premature heat shield ablation failure for the Pioneer $F$ heat source. C. Ablation Mode1 Uncertainties

1. The current APL graphite ablation mode1 is based on a seemingly rational application of available experimental ablation data and assumes a conservative position in the selection of the oxidation and mechanical erosion models in view of current uncertainties within the available data.

2. Uncertainties within the APL model includes formulation on the basis of solely ATJ graphite experimental data and the absence of pressure effects in predicting mechanical erosion. $-26-$ 
Basic uncertainties relative to graphite ablation models in general concern the imprecise knowledge defining the kinetic mechanism(s) of carbon oxidation and the thermodynamic functions and kinetic behavior of higher order carbon vapor species formed during sublimation.

3. Significant refinements in graphite ablation predictive techniques for heat source reentry analysis are contingent upon:

(a) acquiring an extended experimental ablation data base in both the oxidation and sublimation regimes for graphite materials currently being considered in heat source designs; wherein, particular emphasis should be directed toward low pressure data at elevated surface temperature to resolve pressure effects on mechanical erosion.

(b) extending experimental research in the areas of carbon oxidation kinetics and carbon vaporization at elevated temperatures.

\section{Ablation Failure Study}

1. The combined analyses of 15 superorbital reentries using APL's current graphite ablation model identified a Pioneer F heat source ablation failure boundary in $\mathrm{V}-$ : space that commenced at the multiple skip boundary and extended essentially along the $40 \mathrm{~K}$ velocity coordinate. The failure criteria was selected as heat shield burn through at approximately time of impact.

2. The large sensitivity of graphite ablation to changes in the mechanical erosion and oxidation models (as displayed in these studies) suggests that an error analysis which addressed 
SILVER SPRING MARYLAND

these uncertainties would yield minimal fuel release probabilities and not significantly alter the probabilities reported by TeledyneIs otopes. 
VII. REFERENCES

1. R. D. Klett, Pioneer Heat Source Aerothermodynamic Analysis:

Volume II - Aeroheating, Ablation and Design Modifications,

SC-RR-71 0168, Aerospace Nuclear Safety Department, Sandia

Laboratories, Albuquerque, New Mexico, May 1971.

2. D. W. Conn, Comparative Review of Teledyne-Isotopes and Sandia

Laboratories Pioneer F Safety Reentry Thermal Analyses, ANSP-003, Applied Physics Laboratory, Silver Spring, Md., August 1971.

3. J.W. Metzger, et. a1., The Oxidation and Sublimation of Graphite In Simulated Reentry Environments, R66SD54, Missile and Space Division, General Electric Co., Valley Forge, Pa. (also AIAA Preprint No. 65-643, 1965).

4. H. G. Maahs, Ablation Performance of Glass Like Carbons, Pyrolytic Graphite and Artificial Graphite In the Stagnation Pressure Range 0.035 to 15 Atmospheres, NASA TN D-7005, Dec. 1970.

5. I. M. Miller and K. Sutton, An Experimental Study of the Oxidation of Graphite In High Temperature Supersonic and Hypersonic Environment, NASA TN D-3444, July 1966.

6. H. G. Maahs, Oxidation of Carbon at High Temperatures: Reaction Rate Contro1 or Transport Control, NASA TN D-6310, June 1971.

7. J. R. Baron and H. Bernstein, Heterogeneous Rate Coupling For Graphite Oxidation, AIAA Preprint No. 70-823, AIAA 5th Thermophysics Conference, July 1970.

8. L. L. Perini, Review of Graphite Ablation Theory and Experimental Data, ANSP-M-1, Applied Physics Laboratory, Silver Spring, Md., December 1971. 
9. D. B. Spalding, Convective Mass Transfer, McGraw-Hill Book Co., Inc., New York, N.Y., 1963.

10. Users Manual, Aerotherm Equilibrium Thermochemistry Computer Program, Version 3-Volumes I, II, Report UM-70-13, Aerotherm Corporation, Mountain View, California, April 1970.

11. H. N. Browne, et. a1., The Theoretica1 Computation of Equilibrium Compositions, The modynamic Properties and Performance Characteristics of Propellant Systems, NOTS TP 2434, U.S. Naval Ordnance Test Station, China Lake, California, June 1960.

12. Users Manual, Aerotherm Charring Material Thermal Response and Ablation Program, Version 3 -Volumes I, II, Report UM-70-14, Aerotherm Corporation, Mountain View, California, April 1970.

13. J. H. Lunde11 and R. R. Dickey, Graphite Ablation at High Temperatures, AIAA Preprint No. 71-418, AIAA 6th Thermophysics Conference, April 1971.

14. S. M. Scala and L. M. Gilbert, Sublimation of Graphite and Hypersonic Speeds, AIAA Journal Vo1. 3, No. 9, September 1965.

15. T. A. Dolton, et. a1., Thermodynamic Performance of Carbon in Hyperthermal Environments, AIAA Preprint No. 68-754, AIAA 3rd Thermophysics Conference, June 1968.

16. K. S. Pitzer and E. Clementi, Large Molecules in Carbon Vapor, Journal of American Chemical Society, Volume 81, 1959.

17. J. Drowart, et. al., Mass Spectrometric Study of Carbon Vapor, Journal of Chemical Physics, Volume 31, 1959.

18. H. B. Palmer and M. Shelef, Vaporization of Carbon, Chemistry and Physics of Carbon, Volume 4, pp. 85-135, 1968. 
19. SNAP 19/Pioneer F Safety Analysis Report - Volume II, INSD2873-42-2, Teledyne-Isotopes, Timonium, Md., June 1971.

20. Minutes of Preliminary Interagency Nuclear Safety Review, Pioneer/ SNAP 19, January $19-20,1971$.

21. Pioneer F AEC Safety Study - Phase II, Report No. GDC-BTD70-015, Convair Aerospace Division of General Dynamics, San Diego, California, January 1971.

22. L. B. Callis, Time Asymptotic Solutions of Blunt-Body StagnationRegion Flows with Nongray Emission and Absorption of Radiation, AIAA Paper No. 68-663, Los Angeles, California, 1968. 


\begin{tabular}{|c|c|c|}
\hline $\mathrm{c}_{\mathrm{p}}$ & $=$ & Specific heat at constant pressure \\
\hline $\mathrm{D}_{12}$ & $=$ & Binary diffusion coefficient \\
\hline h & $=$ & Combined sensible and chemical enthalpy, $h=c_{p} d T+h^{0}$ \\
\hline $\mathbf{h}^{\circ}$ & $=$ & Heat of formation at $298^{\circ} \mathrm{K}$ \\
\hline $\mathbf{k}_{i}$ & $=$ & Species mass fraction \\
\hline $\mathbf{k}$ & $=$ & Thermal conductivity \\
\hline$\dot{m}$ & $=$ & Mass loss rate per unit area \\
\hline$\dot{\mathrm{m}}^{*}$ & $=$ & Mass loss rate due to particulate erosion \\
\hline$\dot{q}$ & $=$ & Heat transfer rate per unit area \\
\hline$\dot{s}$ & $=$ & Recession rate \\
\hline$t$ & $=$ & Time \\
\hline $\mathbf{T}$ & $=$ & Temperature \\
\hline $\mathbf{V}$ & $=$ & Flight velocity \\
\hline y & $=$ & Distance normal to surface \\
\hline$\gamma$ & $=$ & Flight angle \\
\hline$\rho$ & $=$ & Density \\
\hline$\dot{s} \mathrm{~d} t$ & $=$ & Total recession \\
\hline
\end{tabular}

\section{Subscripts}

c

i

int $=$

$\mathbf{L}$

S

rad in =

rad out =
$=$

$=$

$=$

$=$

$=$

$=$

Convective transfer

Chemical species; inertial frame of reference

Solid conduction transfer

Reference state (e.g., solid)

Transferred state due to chemical transformation

Radiation transfer to surface

Radiation trans fer from surface 
TABLE 1

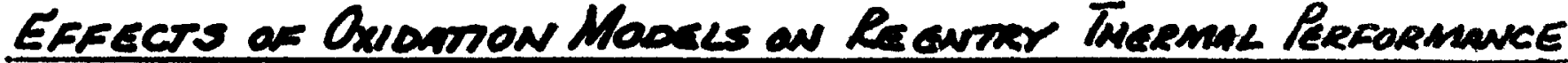

PIONeER F Heat SoUrce

RE ENTRY ORCUTAL DCCAY, LOOK FT RE ENTRY ALTITUDE SIDE ON (ALAT LANOINO) TRIM

INIT TEMPS \& NOMINAL OPCRATION

MODE

$1-D$

MEAT SHELO RECESSHON, INCNES

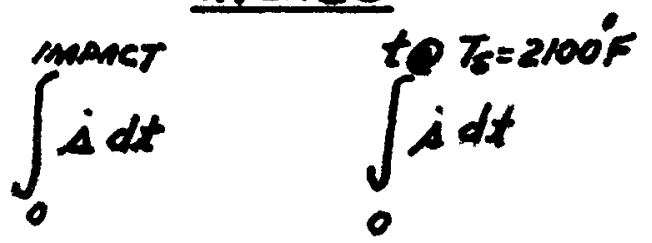

oxionmon mooris

FAST RATE

MODCRATE RATE

VERY SLOW RATE

FAst RATE

MODERATE RATE

VERY SLOW RATE
.102

.184

.092
.135

.131

.092

$1-D$

STRUCTURAL TEMPCRATURE,

PEAK, CLAD

IMPACT, STRENGTH memees

3587

2816

3300

2921

3379

2829

* temperatures shoulo de VIENeD on a comparative casis SINCE A 1-D ANALYSIS OVER PREDICTS MEAT SOUECE CAPSULE TEMPERATURES OY $10.12 \%$. 
THE JOHNS HOPKINS UNIVERSITY APPLIED PHYSICS LABORATORY SILVER SPRING MARYLAND

Table 2

SUMMARY OF ABLATION FAILURE STUDY

PIONEER F HEAT SOURCE

Conditions: Thermochemistry Mode1: Moderate Rate, JANAF(69) Sub1imation Mechanical Erosion: Mode1 No. 1

Attitude: Flat Leading, Side on Stable, Initial Altitude: 400K $\mathrm{ft}$. Initial Temperature: Nominal Operational Mode

\begin{tabular}{|c|c|c|c|c|c|c|c|c|}
\hline \multirow[t]{2}{*}{ Trajectory } & \multirow[t]{2}{*}{$\mathrm{F} / \mathrm{S} / \mathrm{B}$} & \multicolumn{5}{|c|}{ Therma1 Conditions } & \multirow{2}{*}{\multicolumn{2}{|c|}{${ }^{\mathrm{P} \mathrm{s}_{\max }}(\mathrm{atm}) \theta_{\mathrm{q}}$}} \\
\hline & & $\theta(\mathrm{sec})$ & $S(\mathrm{in})$ & $V(f p s)$ & $z(f t)$ & $\mathrm{q} / \mathrm{q}_{\max }$ & & \\
\hline$-6 \times 37 \mathrm{~K}$ fps & $\mathrm{s}$ & 396 & .237 & 256 & 0 & & & \\
\hline$-6 \times 39 \mathrm{~K}$ fps & B & 459 & .283 & 269 & 2935 & & & \\
\hline$-6 \times 40 K$ fps & $\mathrm{F}$ & 501 & .283 & 2667 & 191950 & $\sim 0$ & .28 & 80 \\
\hline$-8 \times 40 \mathrm{~K} f \mathrm{ps}$ & B & 295 & .283 & 258 & 0 & & & \\
\hline$=9 \times 39 \mathrm{~K}$ fps & $\mathrm{s}$ & 273 & .252 & 256 & 0 & & & \\
\hline$-9 \times 41 \mathrm{~K}$ fps & $\mathrm{F}$ & 173 & .283 & 519 & 36840 & $\sim 0$ & 1.3 & 46.2 \\
\hline$=9 \times 43 \mathrm{~K} f \mathrm{ps}$ & F & 52.5 & .283 & 26185 & 134700 & .615 & 1.6 & 42.9 \\
\hline$=12 \times 40 \mathrm{~K}$ fps & B & 206 & .283 & 300 & 10050 & & & \\
\hline$=12 \times 42 \mathrm{~K}$ fps & $\mathrm{F}$ & 37.6 & & 25070 & 121270 & .615 & 2.0 & 32.9 \\
\hline$-12 \times 44 \mathrm{~K}$ fps & F & 32.3 & $\downarrow$ & 34335 & 140655 & .973 & 1.9 & 30.5 \\
\hline$-14 \mathrm{x} 39 \mathrm{~K}$ fps & S & 223 & .266 & 256 & 0 & & & \\
\hline$-14 \times 44 \mathrm{~K}$ fps & F & 42.5 & .283 & 7130 & 87875 & .019 & 2.40 & 28.2 \\
\hline$-16 \times 39 \mathrm{~K}$ fps & $S$ & 212 & .271 & 256 & 0 & & & \\
\hline$-16 \times 41 \mathrm{~K}$ fps & $\mathrm{F}$ & 35 & .283 & 9490 & 88500 & .035 & 2.40 & 25.2 \\
\hline$-16 \times 43 \mathrm{~K}$ fps & $\mathbf{F}$ & 25 & .283 & 32290 & 127290 & .94 & 3.60 & 23.4 \\
\hline
\end{tabular}

Code:

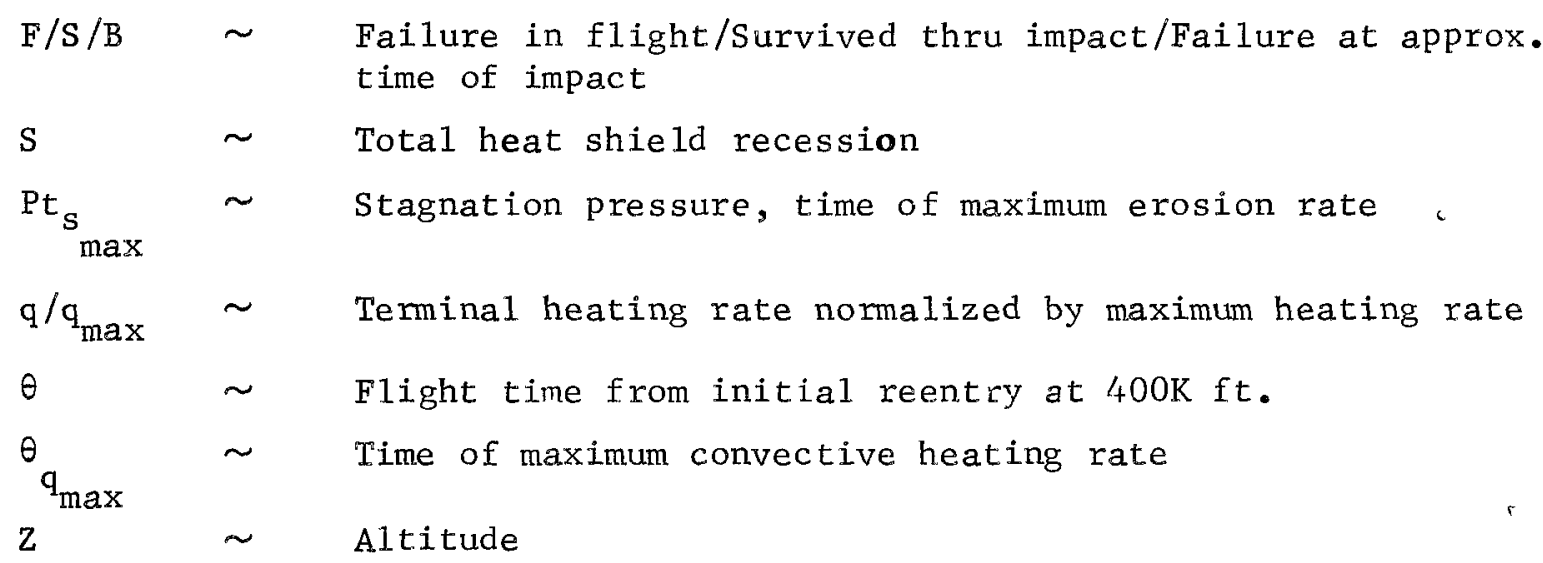


Oxidation Cutrofe Conceat

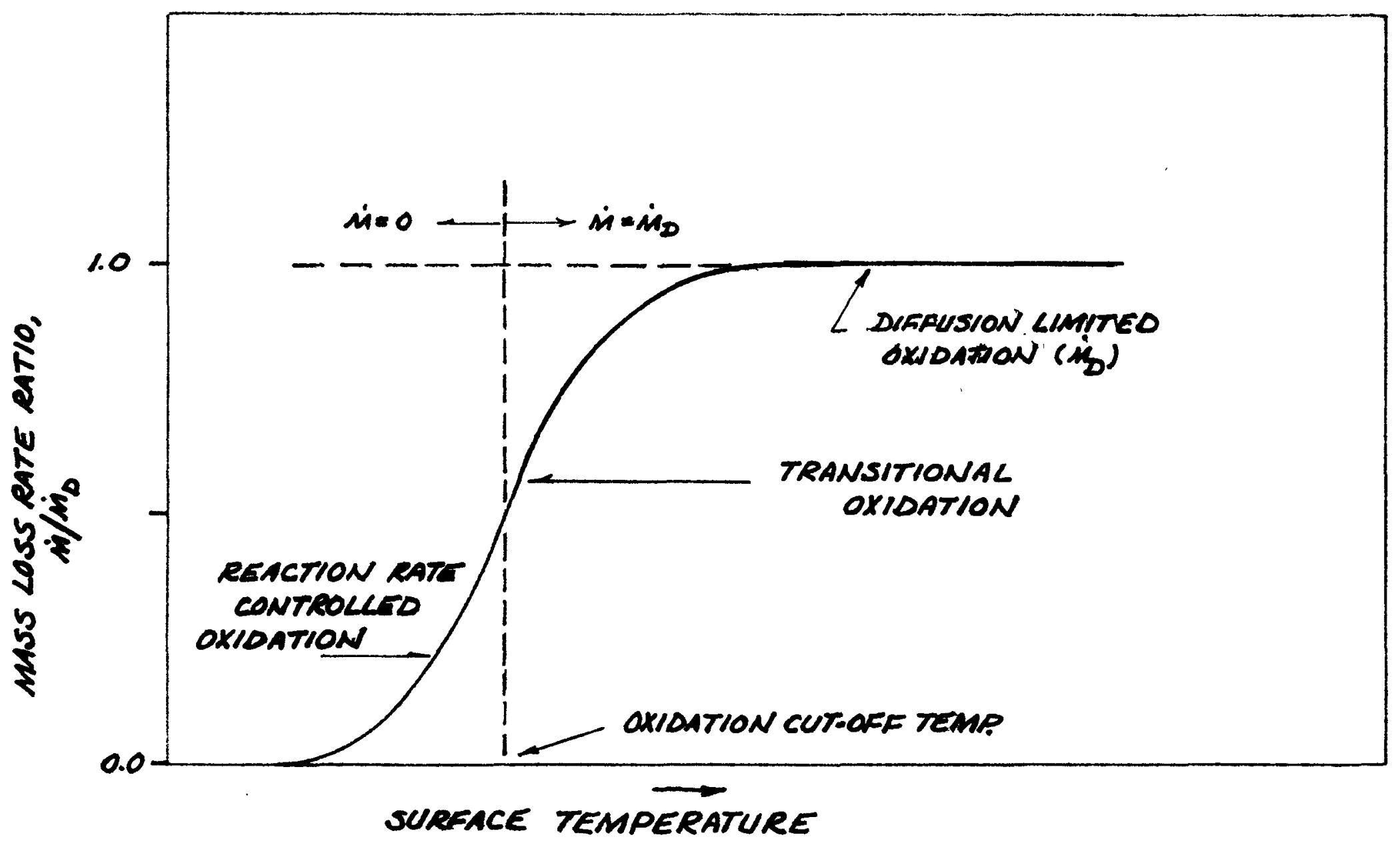

Figure 1 
$11 / 16 / 71$

$T_{w}$. SURFACE TEMPERATURE, ${ }^{\circ} \mathrm{F}$

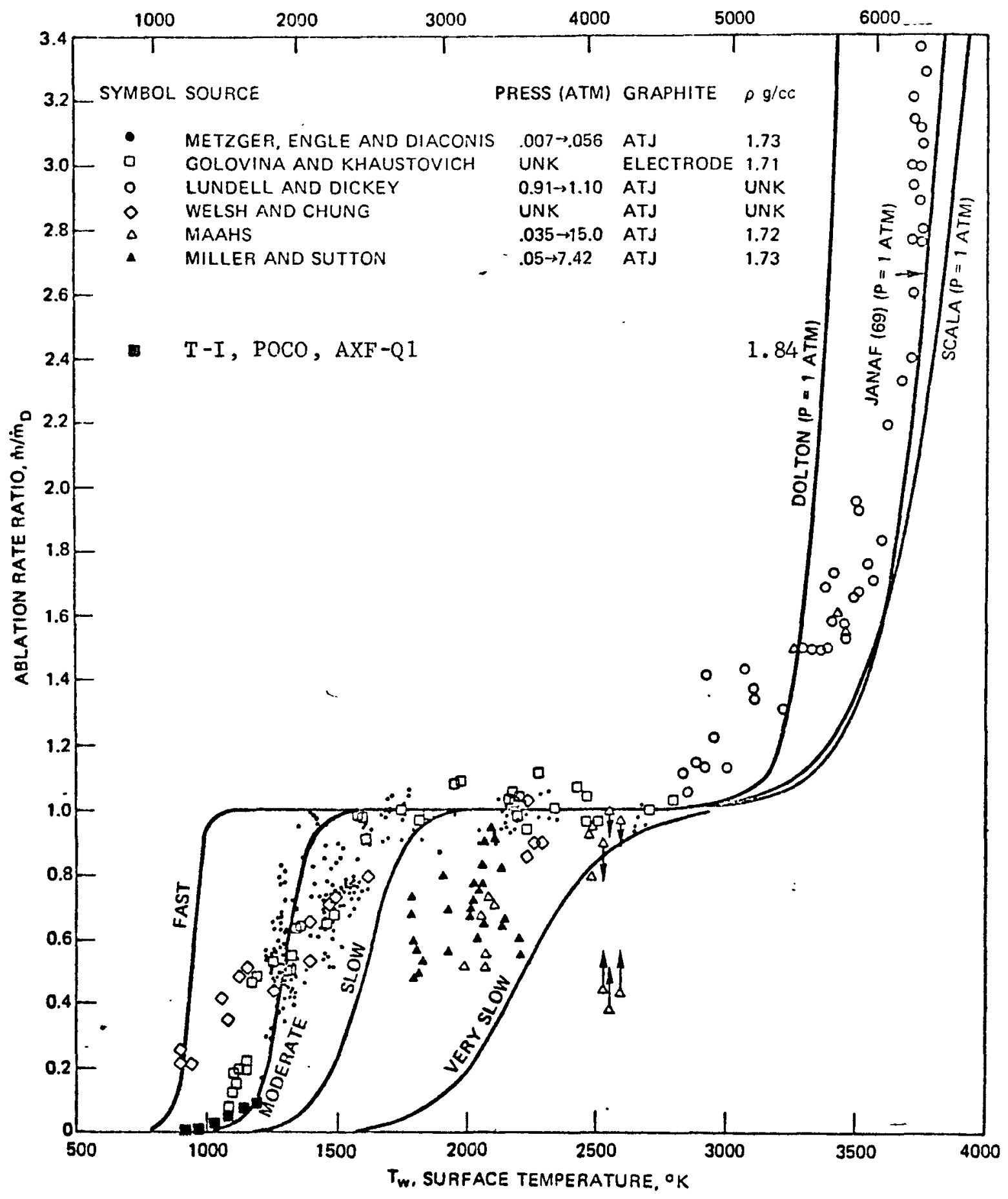

Figure 2. Comparison of Graphite The rmochemical Ablation Models and Experimental Data 


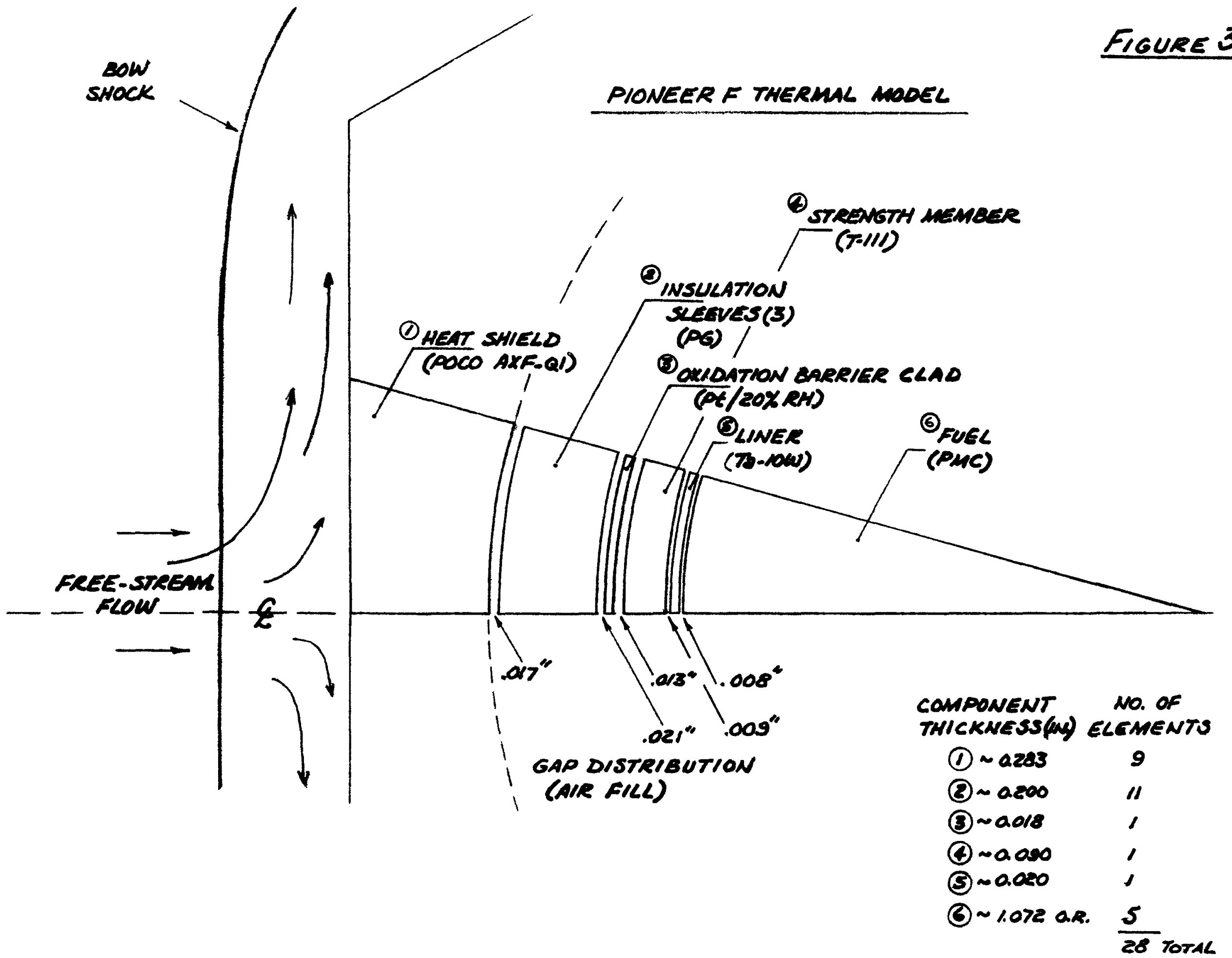


SURFACE EnERgY Balance

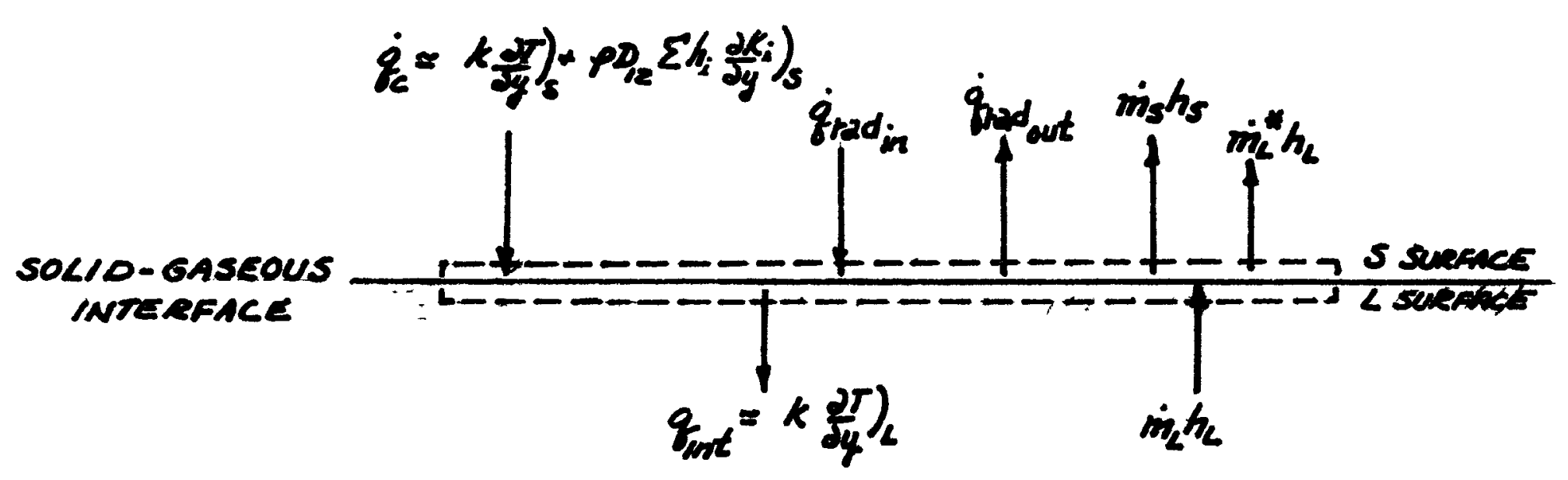

$\dot{q}_{\text {HOd In }}$ N SHOCK LATER RADIATION (INVISCID, NON-GRAY, SELF ABSORPTION, RADIATIVE $\dot{q}_{C} \sim$ CONVECTIVE TRANSFER ( PETRA, KEMP AND RANDELL CORRELATION) grad out SURFACE RAOIATION $\dot{q}_{\text {Int }}$ - SOLID CONDUCTION TRANSFER $\dot{m}_{L} h_{L} \sim$ ENTHALPY FLUX OF CARBON (TOTAL ABLATION RATE) MIL HL - ENTHALPY FLUX OF CARBON (MECHANICAL ABLATION RATE) $\dot{m}_{S} h_{S} \sim$ ENTHALPY FLUX OF VAPORIZED SPECIES (THERMOCHEMICAL ABLATION RATE,

Figure 4 


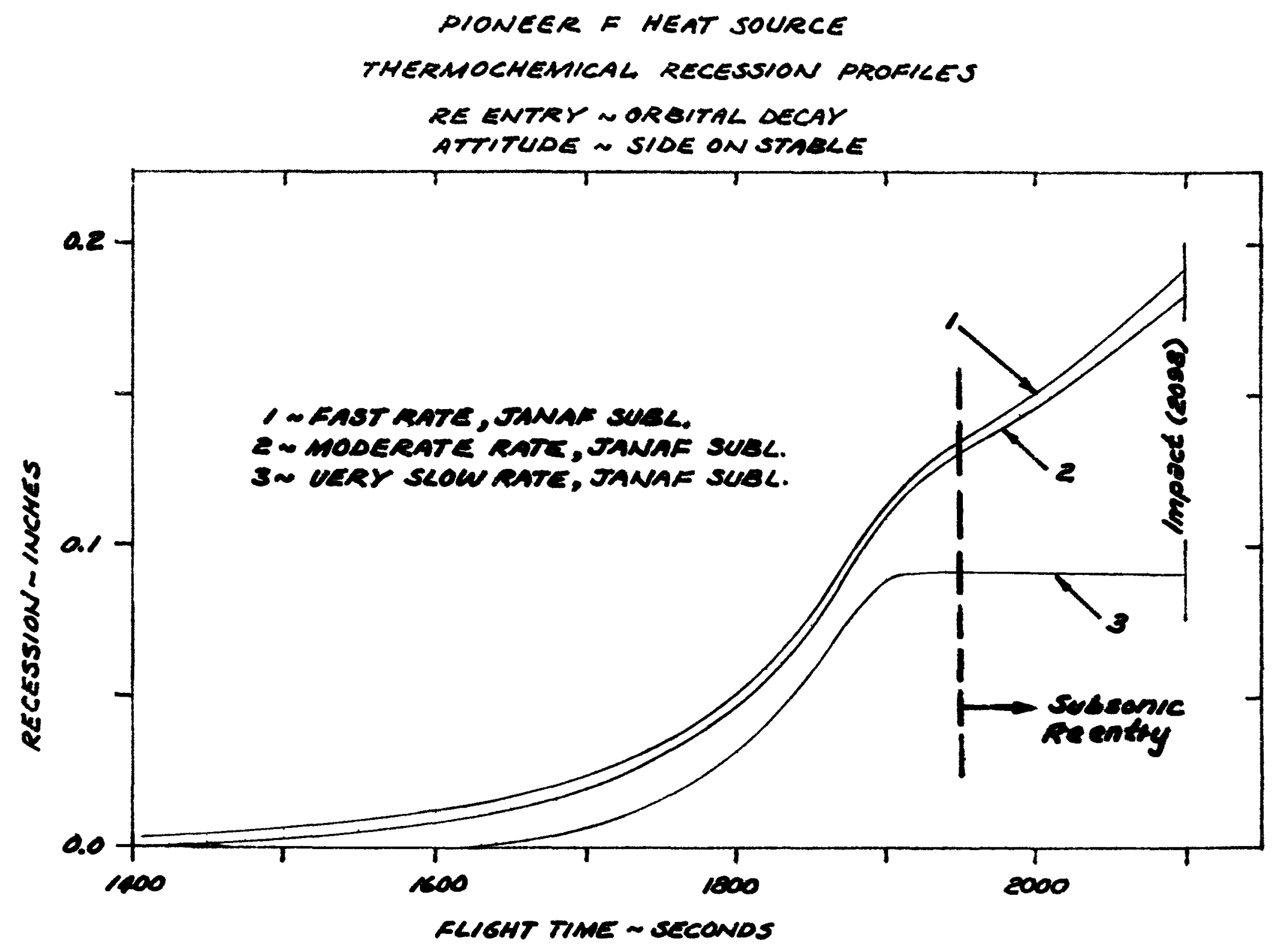

FIGURE 5 
PIONEER F MEAT SOURCE

COMPARISON OF COMPONENT TEMPERATURES FOR DIFFERENT OXIDATION MODELS

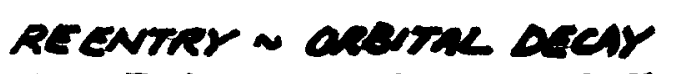
ATTITUDE SNOT ON SMILE

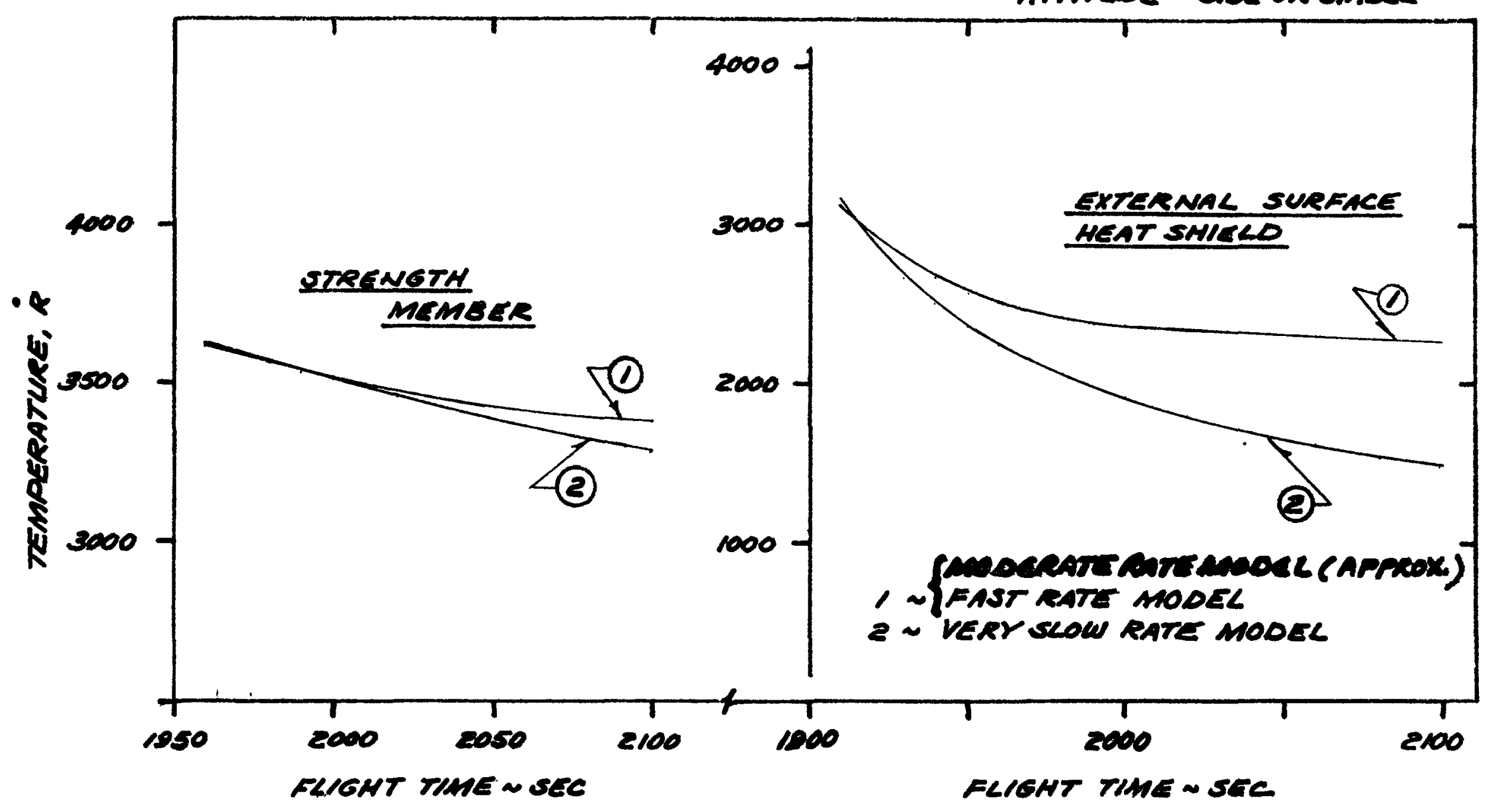

Figure 6 
PIONEER F HEAT SOURCE

THERMOCHEMICAL RECESSION PROFILES

RE ENTEY -8\% 40 KR S, HOOK AT

ATTITUDE SIDE ON STABLE

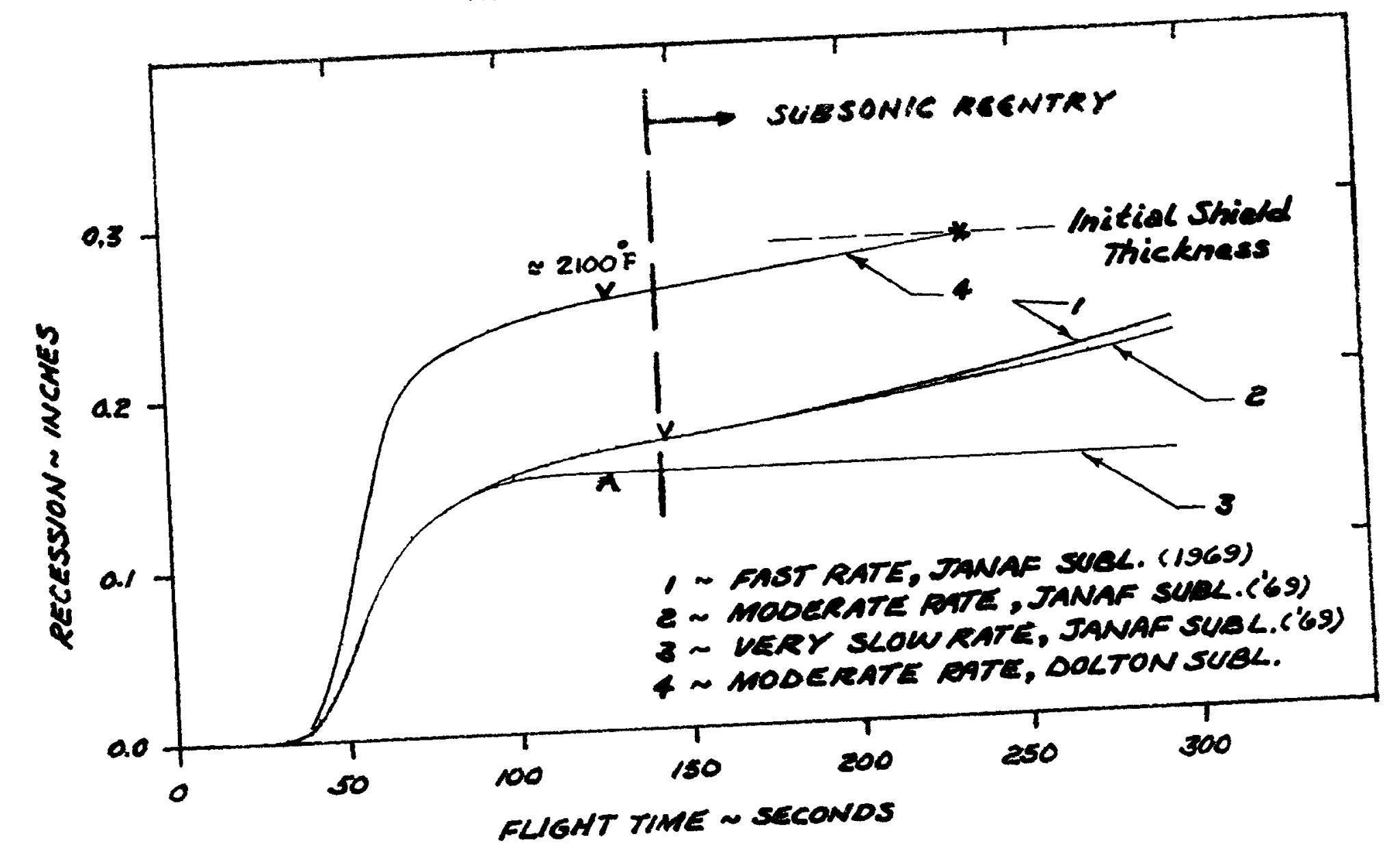

FIGURE? 
MECHANICAL EROSION MODELS

EXP DATA SOURCE LUNDELL SODICKEY (ATJ GRAPHITE)

THERMOCHAM MODEL MODERATE RATE, JANAF (GS) SUOL.

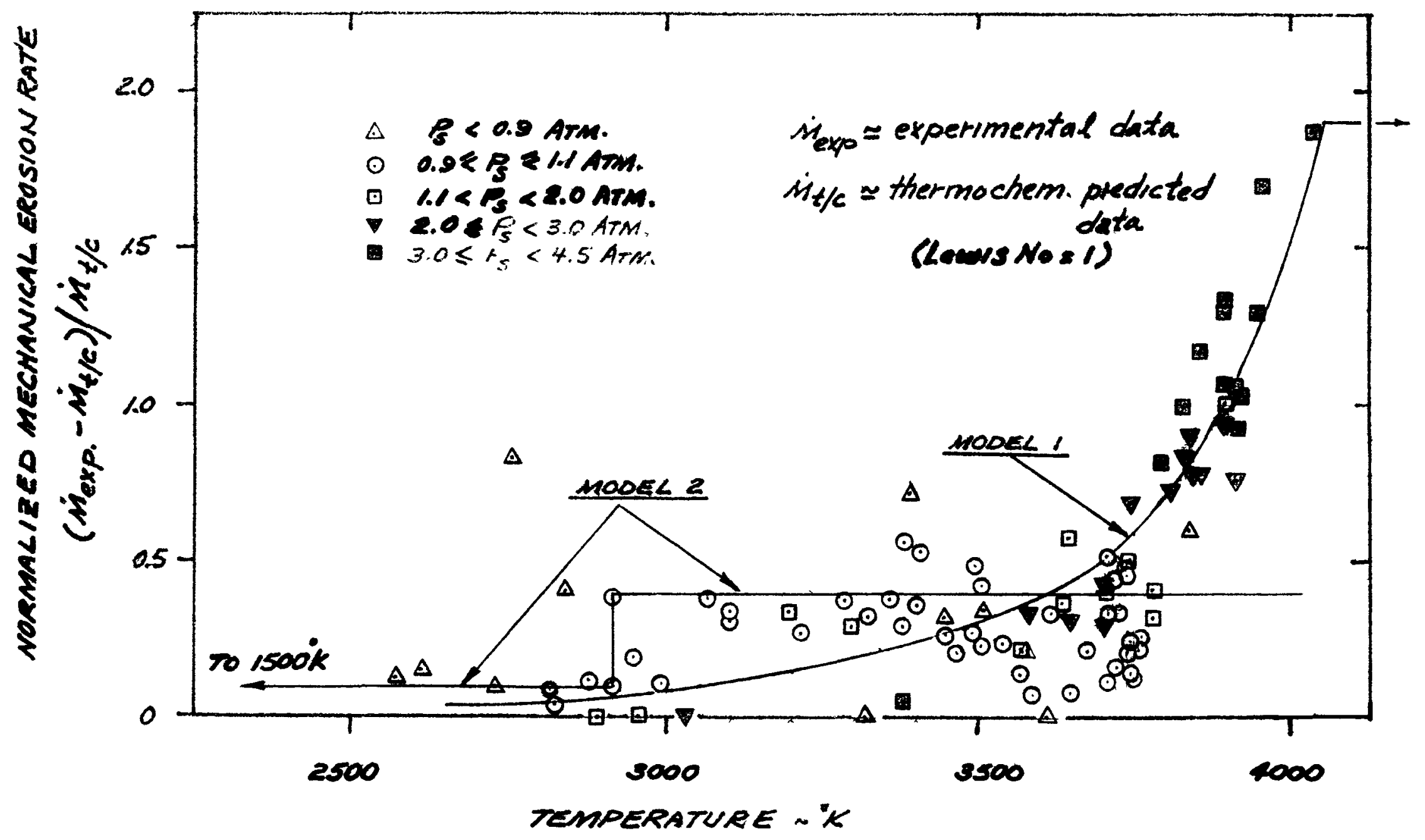

Figure 8 


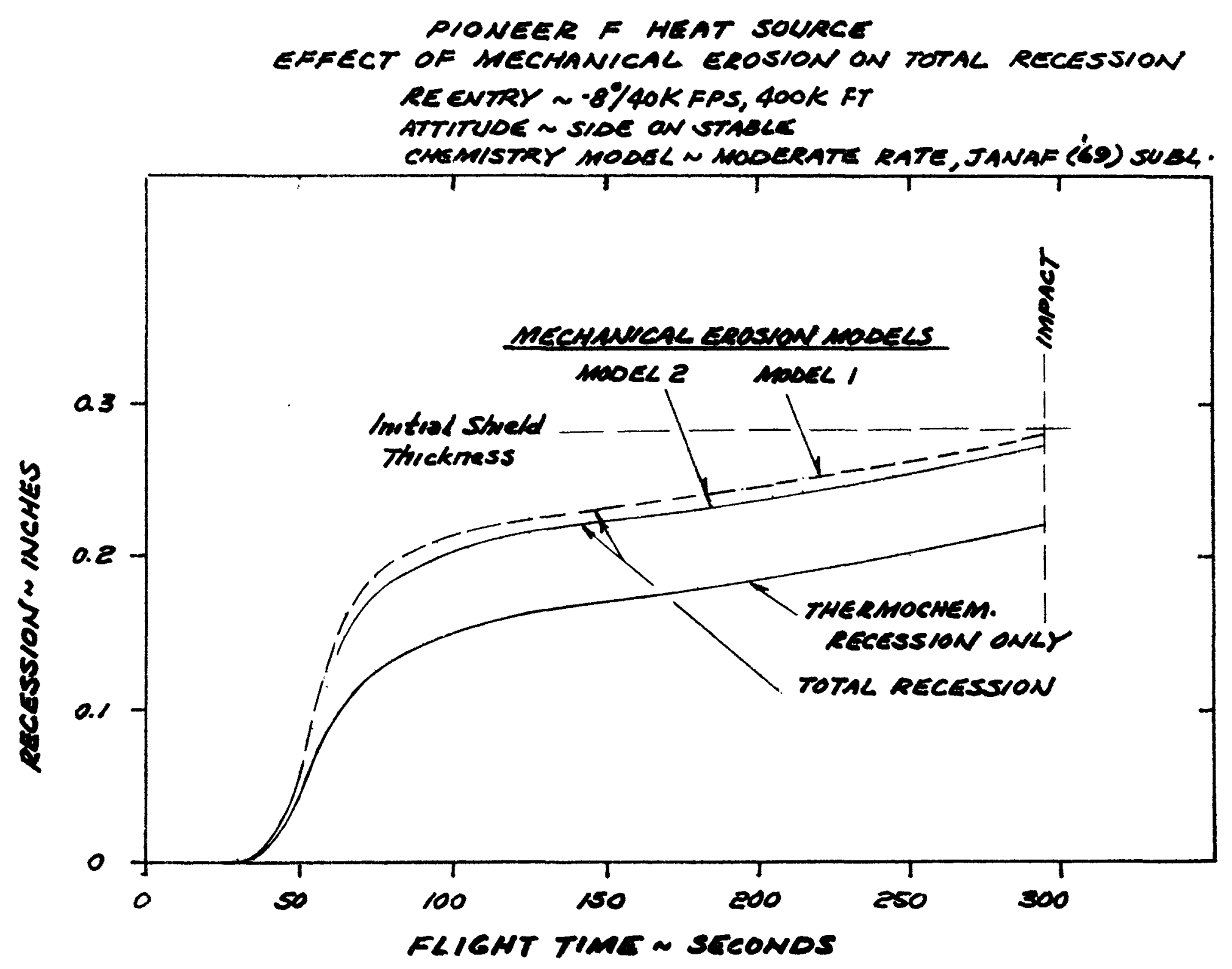

Figure 9 


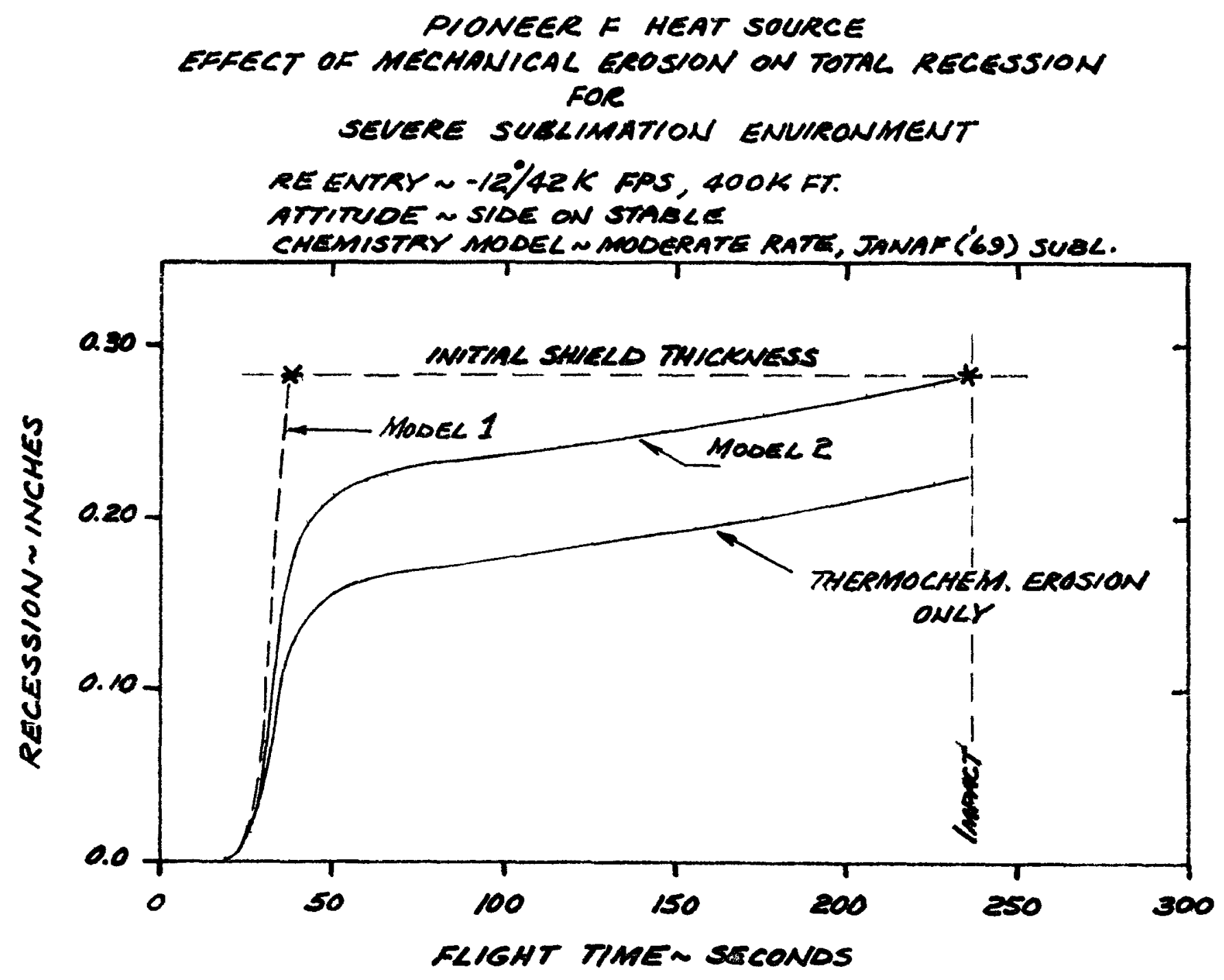

Figure 10 


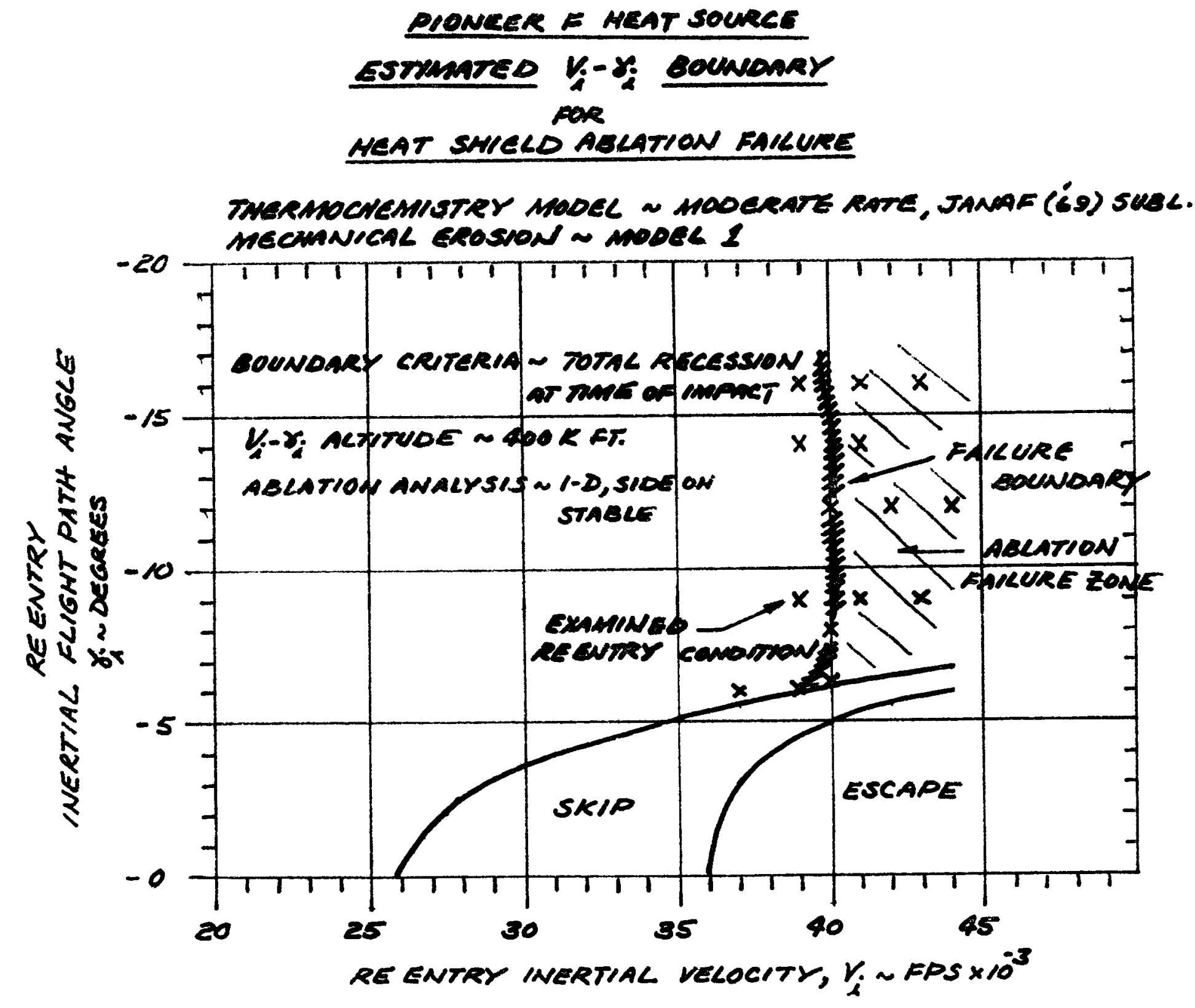

Figure II 
provere E MEAT sourat

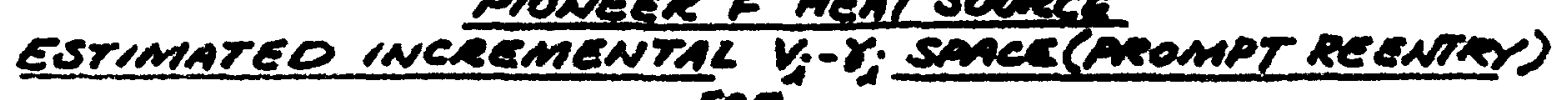

ran

ATMOSPMCRIC FUTL RELCASE

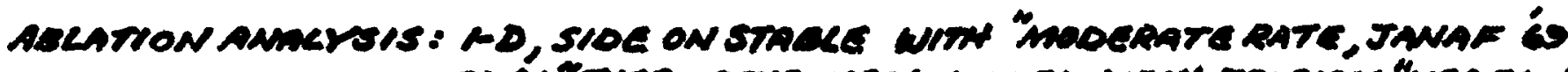

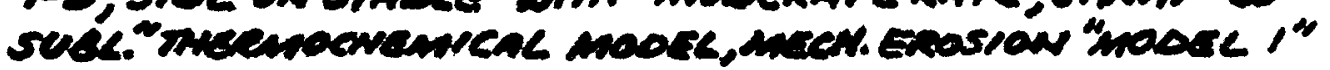

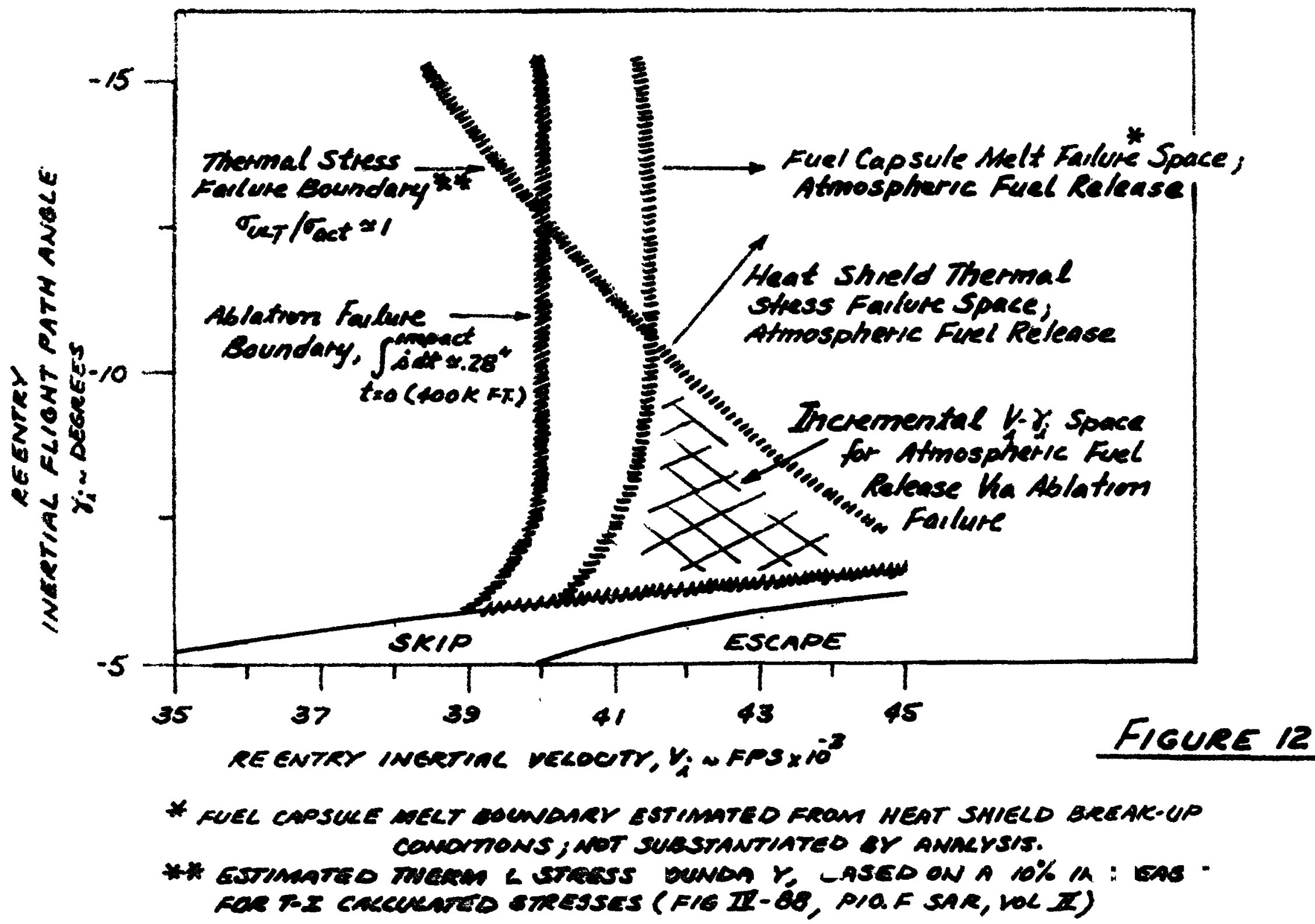

